\title{
Nanotubular surface modification of metallic implants via electrochemical anodization technique
}

This article was published in the following Dove Press journal:

International Journal of Nanomedicine

17 September 2014

Number of times this article has been viewed

\author{
Lu-Ning Wang' \\ Ming Jin' \\ Yudong Zheng' \\ Yueping Guan' \\ Xin Lu' \\ Jing-Li Luo ${ }^{2}$
}

ISchool of Materials Science and Engineering, University of Science and Technology Beijing, Beijing, People's Republic of China;

${ }^{2}$ Department of Chemical and

Materials Engineering, University

of Alberta, Edmonton, AB, Canada
Correspondence: Lu-Ning Wang

School of Materials Science and Engineering, University of Science and Technology Beijing, No. 30, Xueyuan Road, Hai-Dian District, Beijing, I00083,

People's Republic of China

Tel +86 I0 62332184

$\mathrm{Fax}+861062332184$

Email luning.wang@ustb.edu.cn

Jing-Li Luo

Department of Chemical and Materials Engineering, University of Alberta,

9107 - 116 Street, Edmonton,

AB,T6G 2V4, Canada

Tel +I 7804922232

Fax +I 7804922880

Email luoj@ualberta.ca
Abstract: Due to increased awareness and interest in the biomedical implant field as a result of an aging population, research in the field of implantable devices has grown rapidly in the last few decades. Among the biomedical implants, metallic implant materials have been widely used to replace disordered bony tissues in orthopedic and orthodontic surgeries. The clinical success of implants is closely related to their early osseointegration (ie, the direct structural and functional connection between living bone and the surface of a load-bearing artificial implant), which relies heavily on the surface condition of the implant. Electrochemical techniques for modifying biomedical implants are relatively simple, cost-effective, and appropriate for implants with complex shapes. Recently, metal oxide nanotubular arrays via electrochemical anodization have become an attractive technique to build up on metallic implants to enhance the biocompatibility and bioactivity. This article will thoroughly review the relevance of electrochemical anodization techniques for the modification of metallic implant surfaces in nanoscale, and cover the electrochemical anodization techniques used in the development of the types of nanotubular/ nanoporous modification achievable via electrochemical approaches, which hold tremendous potential for bio-implant applications. In vitro and in vivo studies using metallic oxide nanotubes are also presented, revealing the potential of nanotubes in biomedical applications. Finally, an outlook of future growth of research in metallic oxide nanotubular arrays is provided. This article will therefore provide researchers with an in-depth understanding of electrochemical anodization modification and provide guidance regarding the design and tuning of new materials to achieve a desired performance and reliable biocompatibility.

Keywords: nanotubular arrays, anodization, implant, bioactivity, in vitro, in vivo

\section{Introduction}

Implantable biomaterials have been extensively applied to treat hard tissue disorders. It has been reported that 4.5 million Americans are living with artificial knees, including an estimated 500,000 who have had at least two replacement operations on the same knee. ${ }^{1,2}$ In 2011 alone, more than 600,000 knee replacements were performed in the US. ${ }^{1,3}$ The basic requirement for the property of the materials used in orthopedic and orthodontic application is their mechanical strength and these materials must also possess high resistance to corrosion and wear, to prevent weakening of the mechanical properties and the release of toxic species or debris in physiological culture. In addition, materials for implant must provide the ability to be machined to form complex shapes. Specifically important, implantable materials must exhibit biocompatibility to avoid adverse biological response and to minimize allergic immune reactions. ${ }^{4}$ Materials are also required to form a firm and lasting interface with bone in order to survive and function properly. Metals, ceramics, and polymers are three major 
classes of materials adapted in biomaterials. ${ }^{5-8}$ Among them, biologically compatible metals best satisfy the requirements for implants. The most widely used ones are surgical stainless steels (such as 316L and 317), 9,10 Ti and its alloys (such as cp-Ti and Ti6Al4V), ${ }^{11,12} \mathrm{CoCr}$ alloys (such as CoCrMo and CoCrNiMo), ${ }^{13}$ and Ta. ${ }^{14}$ Surgical stainless steels are mainly used for temporary implants since the immune system's reaction to nickel can cause potential complications. ${ }^{10}$ The use of Ti and its alloys is owing to their high specific density and corrosion resistance. Additionally, Ti alloys with relatively lower moduli than other metals are a better match with the modulus of bone. ${ }^{11,12}$ Pure Ti and Ti6Al4V are the prevalent metals used for orthopedic and orthodontic applications. Because of the concern over the potential toxicity of $\mathrm{V}$ and mutagenicity of $\mathrm{Al}$, new $\mathrm{Ti}$ alloys were also developed by substituting $\mathrm{Al}$ and $\mathrm{V}$ with other less toxic elements such as $\mathrm{Nb}$, Ta, and $\mathrm{Zr} .{ }^{15,16} \mathrm{CoCr}$ alloys are encountered in the application of artificial knee and hip joints owing to the higher strength, excellent corrosion, and wear resistance. However, their high stiffness causes the adjacent bone to be stressshielded and results in disuse atrophy. ${ }^{13}$ Ta is considered as the most corrosion resistant metal and is being exploited to create a highly porous form that favors bone ingrowth and achieves implant fixation. ${ }^{14} \mathrm{Zr}$ has also received increasing attention because it shares similar properties as Ti and exhibits lower magnetic susceptibility. These advantageous properties make it possible to use them in downsized, safe, and magnetic resonance imaging-compatible devices in medicine. $^{15}$

When exposed to physiological culture after the surgical injury, metallic implants are able to form stable and compact oxide layers such as $\mathrm{Cr}_{2} \mathrm{O}_{3}$ (for stainless steels and CoCr alloys), ${ }^{9,13} \mathrm{TiO}_{2}$ (for $\mathrm{Ti}$ and its alloys), ${ }^{11}$ and $\mathrm{Ta}_{2} \mathrm{O}_{5}$ (for tantalum). ${ }^{14}$ These layers insulate the reactive underlying metal from the surrounding environments and prevent the transmission of undesirable ions. Moreover, the existence of oxide layers also makes metal materials bioinert, resulting in fibrous capsules surrounding implants. ${ }^{17}$ These fibrous tissues form because of the body's protective mechanism against any materials recognized as being foreign. On the other hand, bone generation competes with the rejection response. ${ }^{18}$ Osteoblasts are differentiated from progenitor cells, migrating to the implant site, and secreting collagen to mineralize into new bone. ${ }^{8,19}$ The interaction between bone and implant is crucial to determine the performance and life span of the implant. An immediate bone-implant contact is highly desired to secure the mechanical stability. On the contrary, the formation of fibrous tissues retards the contact between bone and implants, which can result in a weak mechanical bonding and cause the implant to loosen with a failed implantation as the consequence. ${ }^{20}$

Current implantable metals typically develop a thin layer of fibrous tissue at the bone-implant interface. The existence of this thin layer becomes a major challenge to decelerate the process of osseointegration and to extend the implant fixation time. Fast fixation is critical for the success rate of implantation and can reduce the micro-motion of implants and minimize the formation of fibrous tissue, leading to early physiologic loading and preventing the bone from disuse atrophy. ${ }^{20}$ In addition, fast fixation of implants reduces the hospitalization time, cost, and improves the quality of life for patients. As a result, many attempts have been made to improve the interaction between bone and implants. One of the most actively pursued areas is the development of novel surfaces by modification techniques to improve the implants' surface properties and facilitate faster osseointegration and healing process. ${ }^{20}$

Basic bone composition consists of mostly fibrous protein collagen, carbonated apatite $\left[\mathrm{Ca}_{5}\left(\mathrm{PO}_{4}, \mathrm{CO}_{3}\right)_{3}(\mathrm{OH}), \mathrm{CAP}\right]$, and water. ${ }^{21,22}$ Some previous studies indicated that bone contains many different structures and is highly porous on the micrometer scale. ${ }^{23-25}$ A current strategy is to consider natural bone as a nanostructured material. ${ }^{26}$ The type I collagen, which is the organic matrix of bone, has a triple helix structure with $300 \mathrm{~nm}$ in length, $0.5 \mathrm{~nm}$ in width, and periodicity of $67 \mathrm{~nm} .{ }^{26}$ Bone consists of $\sim 70$ weight (wt) $\%$ CAP, the inorganic mineral phase of bone which is about $20-40 \mathrm{~nm}$ in length and is uniquely patterned within the collagen network. ${ }^{27-29}$ Considering the geometric factors of collagen and CAP, bone cell may be used in a nanoscale environment rather than microscale. Thus, proper nanoscale surface modification methods on metallic implants are highly desired to achieve better and more rapid bonding to bone.

An electrochemical technique known as anodization or anodic oxidation is a well-established surface modification approach for metals to produce protective layers. ${ }^{30}$ It has been successfully applied as a surface treatment for orthopedic implants in the past several decades and has achieved some new advances on the fabrication of nanostructured surfaces in recent years. ${ }^{31-36}$ Particularly, self-organized nanotubular oxide structures can easily be formed and controlled by varying the anodic conditions. ${ }^{37-43}$ This type of self-aligned nanotubular structure has attracted more interest than others over the past 10 years. More than 1,000 papers related to this topic have been published over the past 5 years according to the publication statistics. ${ }^{31,36,42}$ Without hesitation, Ti-based metals have been paid more attention and represent an attractive model system for exploring this nanotechnology to create 
more effective implantable devices; self-assembled $\mathrm{TiO}_{2}$ nanotubular layer can be readily fabricated on Ti implants to satisfy the requirement for biomedical applications. ${ }^{44,45}$ Further, remarkably, the self-ordering anodization approach is not only limited to $\mathrm{Ti}$ and Ti-based alloys but can also be applied to a large range of other transition metals or alloys to form highly ordered nanoporous or nanotubular oxide layers for potential biomedical applications. ${ }^{46-50}$ For these reasons, this review focuses on up-to-date research that describes the synthesis of these nanotubular structures and the factors that influence the degree of self-ordering, tubular geometry, and crystal structure. Although previous publications have addressed the application of nanotubular arrays on photocatalytical applications, we mainly focus on the biomedical application of this interesting structure. Particularly bioactivity, biocompatibility, and physiological responses of these nanotubular layers on $\mathrm{Ti}$ and other valve metals pertaining to biological culture for orthopedic applications will be discussed. The final section summarizes the main points of this chapter and provides perspectives for future work in this field.

\section{Fabrication of nanotubular arrays via electrochemical anodization technique}

Electrochemical anodization has been used to fabricate thick and uniform oxide layers on metals (normally referred to as valve metals) for almost several decades. Most recently, it has been established that a self-organized nanoporous and nanotubular oxide layer can be grown on suitable metals. ${ }^{31,36,38,51-56}$ When most of the valve metals ( $\mathrm{M}$ as a representative symbol of metal) are exposed to an anodic voltage in an electrochemical configuration as shown in Figure $1,31,32,55$ an oxidation reaction will be initiated at metal-oxide interface as $\mathrm{M} \rightarrow \mathrm{M}^{\mathrm{n}+}+\mathrm{ne}^{-}$and the $\mathrm{M}^{\mathrm{n}+}$ ions migrate outward under the applied voltage. Meanwhile, $\mathrm{O}^{2-}$ ions afforded by $\mathrm{H}_{2} \mathrm{O}$ in the electrolyte migrate toward the metal-oxide interface, and react with $\mathrm{M}^{\mathrm{n}+}$ to form a compact metal-oxide film $\left(\mathrm{MO}_{\mathrm{x}}, \mathrm{x}\right.$ depends on the valence of the metal). The anodization system is normally under a constant applied voltage. As the $\mathrm{MO}_{\mathrm{x}}$ has higher resistivity than the electrolyte and the substrate, the applied field within $\mathrm{MO}_{\mathrm{x}}$ is progressively reduced by the increasing oxide thickness. Although the oxide film keeps thickening as long as the applied field is high enough to drive the ion conduction through the oxide, the process continuously slows down and ends up with a finite thickness (equilibrium state) of the $\mathrm{MO}_{\mathrm{x}}$ film. However, certain experimental conditions may

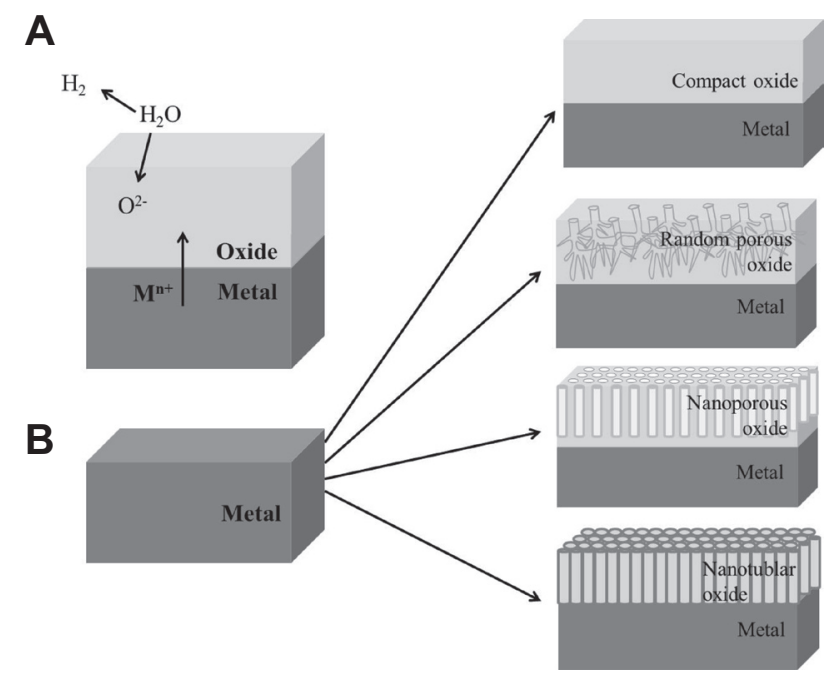

Figure I

Notes: (A) Mechanism of oxide formation on valve metals. (B) Various morphologies obtained by electrochemical anodization of valve metals - a compact oxide film, a disordered porous oxide layer, a self-ordered nanoporous or a self-ordered nanotubular layer. Copyright (C) 2009. Reproduced by permission of the Royal Society of Chemistry, from Ghicov A, Schmuki P. Self-ordering electrochemistry: a review on growth and functionality of $\mathrm{TiO}_{2}$ nanotubes and other self-aligned $\mathrm{MO}_{x}$ structures. Chem Commun (Camb). 2009;(20):279I-2808. ${ }^{11}$

warrant further growing of porous $\mathrm{MO}_{\mathrm{x}}$ layers, and under more specific conditions, self-assembled nanoporous and nanotubular layers can be achieved.

Masuda et al first reported that a self-organized nanoporous alumina layer could be fabricated on aluminum in oxalic acid under specific voltage conditions. ${ }^{57}$ This remarkable work has been considered as a milestone in the field of anodization of metal and has triggered hundreds of papers describing the later achievements in the fabrication, modification, and application of nanoporous alumina. ${ }^{58-65}$ The as-formed nanoporous alumina was used as photonic crystals and a template for nanomaterials' synthesis. ${ }^{56-60}$ Accordingly, several models have been put forward to explain the growth mechanism of the self-organized alumina nanoporous layers. ${ }^{31,36}$ A descriptive, stepwise explanation is schematically shown in Figure 2. ${ }^{31}$

Briefly, as a result of the onset of electrochemical anodization in acidic conditions, the surface of aluminum is covered entirely by a compact, uniform anodic alumina oxide layer (Figure 2A). Since the surface of oxide layers fluctuates at the microscopic level, the distribution of electric field in the oxide layer is non-uniform, resulting in focused electric field at certain places, as shown in Figure 2B. Consequently, field-enhanced dissolution in the anodic oxide takes place and the nanopores start to form (Figure 2C). Successively, the nanopore growth process reaches a steady-state and uniformly distributed pores are obtained (Figure 2D). Additionally, the self-ordering of nanoporous alumina layers is also 


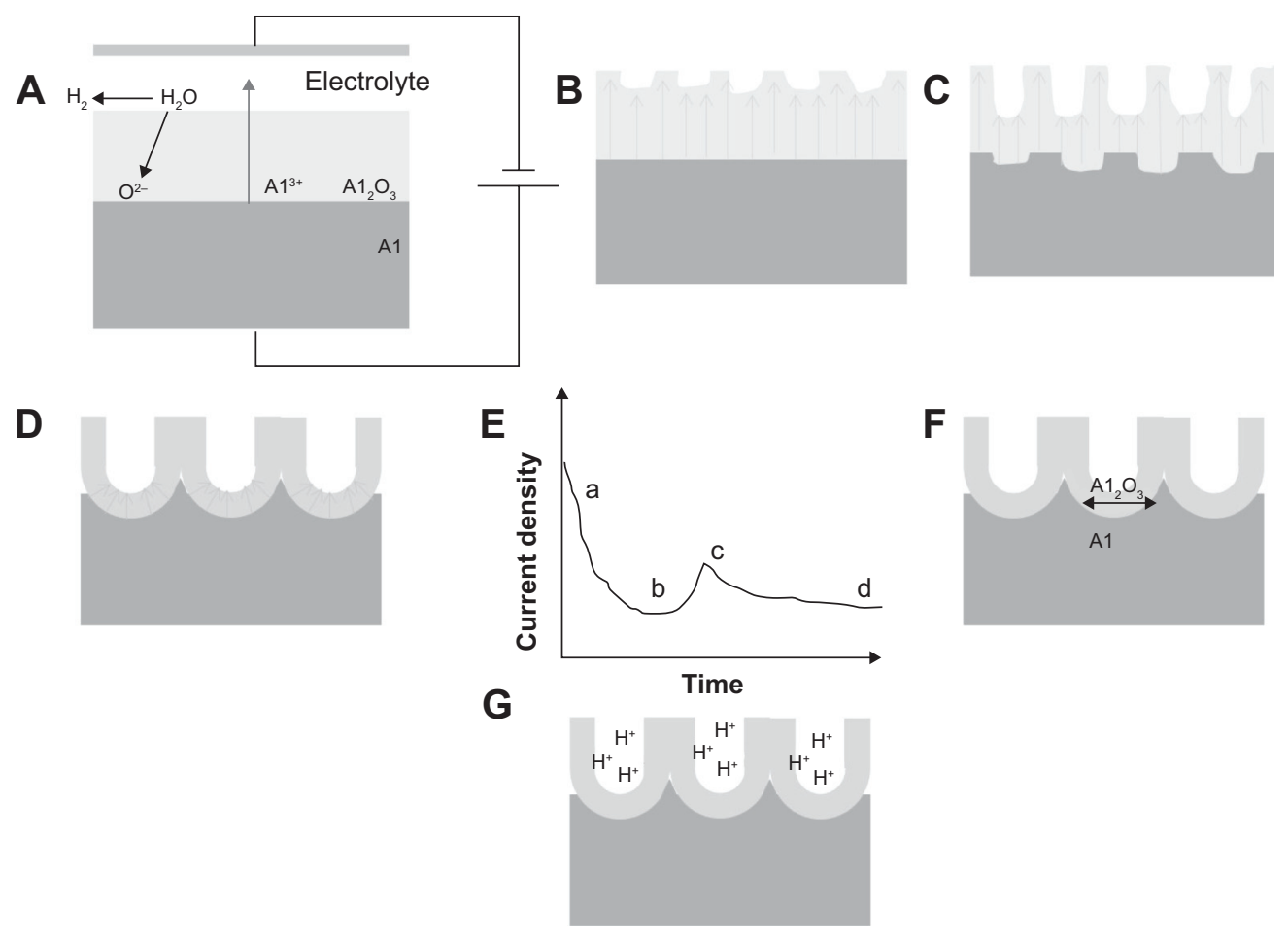

Figure 2 Schematic representation of alumina pore formation by electrochemical anodization.

Notes: (A) Formation of the anodic oxide on aluminum; (B) local field distribution correlated to the surface morphological fluctuations; (C) initiation of the pore growth due to the field-enhanced dissolution; (D) pore growth in steady-state conditions; (E) represents the current transient recorded during anodization of Al process related to (a)-(d); (F) and (G) show the influence of the volume expansion and the local acidity on the alumina pore growth, respectively. Copyright (C) 2009. Reproduced by permission of the Royal Society of Chemistry, from Ghicov A, Schmuki P. Self-ordering electrochemistry: a review on growth and functionality of TiO ${ }_{2}$ nanotubes and other self-aligned MO structures. Chem Commun (Camb). 2009;(20):279I-2808. ${ }^{31}$

contributed by the stress at the metal-oxide interface owing to volume expansion or electrostriction, repulsion of electric fields, or stabling maximum current-flow conditions. Many of the mechanisms for self-organized nanoporous alumina layers can be transferred to the formation of self-ordering nanopores and nanotubular layers on other metals such as $\mathrm{Ti}, \mathrm{Zr}$, Ta, etc. ${ }^{31,43,51}$ However, for these metals, in contrast to aluminum, an acidic condition (or a low $\mathrm{pH}$ condition) is not sufficient to create self-ordering porous metallic oxide layers but only to form a compact oxide layer. ${ }^{30,31,36}$ In order to form self-ordering nanoporous and nanotubular oxide layers, the existence (or presence) of fluoride ions $\left(\mathrm{F}^{-}\right)$in electrolyte is strictly desired..$^{30,38,41} \mathrm{~A}$ key feature of the $\mathrm{F}^{-}$ions is their ability to form water soluble metal-fluoride complexes. The complex formation aids the prevention of $\mathrm{MO}_{\mathrm{x}}$ layers from formation at the tubular bottom, but this also leads to mild but permanent chemical dissolution of the $\mathrm{MO}_{\mathrm{x}}$. Another important factor is that $\mathrm{F}^{-}$ions are very small and can compete with $\mathrm{O}^{2-}$ migration through the oxide layer. ${ }^{31,36,38}$ It has been observed that $\mathrm{F}^{-}$ions may migrate at a rate twice as high as $\mathrm{O}^{2-}$ ions through oxide lattices. ${ }^{31,36,47}$ As a result, a fluoride rice layer is formed at the metal-oxide interface. This layer is believed to be the origin of the nanotubular separation and formation. Several excellent reviews have well explained the formation mechanism of $\mathrm{MO}_{\mathrm{x}}$ nanotubular arrays by means of electrochemical anodization. This section, therefore, will only give a brief summary on the formation of some $\mathrm{MO}_{\mathrm{x}}$ nanotubular arrays under various conditions. ${ }^{31,36,38}$

\section{Self-ordering $\mathrm{TiO}_{2}$ nanotubular arrays}

According to the publication statistics, it is believed that the very first paper regarding the formation of porous $\mathrm{TiO}_{2}$ oxide layers on $\mathrm{Ti}$ via electrochemical anodization in $\mathrm{F}^{-}$containing electrolyte was presented by Kelly in 1979. ${ }^{66}$ However, owing to the insufficient information of surface morphology by microscale observation, it was difficult to find the self-ordering $\mathrm{TiO}_{2}$ nanoporous arrays from their work, which accounts for relatively low citation by other researchers. It is well accepted that the formation of self-ordering $\mathrm{TiO}_{2}$ nanoporous structure by anodization in fluoride containing chromic acid was reported by Zwilling et al in $1999 .{ }^{67}$ They pointed out that a small amount of fluoride ions $\left(\mathrm{F}^{-}\right)$in the electrolyte is the key to form self-ordering $\mathrm{TiO}_{2}$ nanoporous structures. Following this pioneer work, several research groups have carried out extensive work on 
optimization of the anodization conditions to develop selfordering nanotubular arrays. ${ }^{31,38}$

Anodization that forms nanotubular layers is usually carried out by ramping a potential step at a constant voltage normally between $1-30 \mathrm{~V}$ in aqueous electrolytes or $5-150 \mathrm{~V}$ in non-aqueous electrolytes containing approximately $0.05-0.5 \mathrm{M} \mathrm{F}^{-} \cdot{ }^{39,41,46,47}$ Crucial factors on fabrication of $\mathrm{MO}_{\mathrm{x}}$ nanotubular arrays are considered to be the applied potential, fluoride concentration, $\mathrm{pH}$ value, and anodization duration. ${ }^{31,38}$ In general, the nanotubular diameter is reported to be linearly dependent on the applied anodic potential during growth. ${ }^{31,36-38}$ Yasuda et al found that the diameter of $\mathrm{TiO}_{2}$ nanotubes correlates linearly with the growth factor, $f_{\text {growth }}$, of the Ti, where $f_{\text {growth }}$ is growth factor and is $2.5 \mathrm{~nm} \cdot \mathrm{V}^{-1}$ for $\mathrm{TiO}_{2}\left(f_{\text {growth }}\right.$ being $f_{\text {growth }}=t_{\text {film }} / U, t_{\text {film }}$ being the compact oxide thickness that grows at a specific potential in Ti). ${ }^{68}$ By assuming that anodic oxide growth begins from a local oxide breakdown site or a point source on the Ti surface, the oxide growth would take place immediately in all directions, leading to a hemispherical oxide structure with a certain radius $R=f_{\text {growth }} U$. Based on this estimation, $\mathrm{TiO}_{2}$ nanotubular diameters from 5 to about $700 \mathrm{~nm}$ can be achieved in the anodization potential range that has been listed above. ${ }^{31}$ Typically, at the early stage of growth, the $\mathrm{TiO}_{2}$ nanotubular length is controlled by the applied electric field and as a result, the nanotubular thickness is proportional to the applied voltage. Under the constant voltage $\mathrm{U}$, the electric field is defined as $F=\mathrm{U} / \mathrm{d}$, where $\mathrm{d}$ is the nanotubular thickness. The electric field keeps dropping constantly as the $\mathrm{d}$ increases, thus lowering the driving force for solid-state ion ( $\mathrm{such}$ as $\mathrm{Ti}^{4+}$ ) migration. ${ }^{38}$ The consequence is an exponential drop in the anodic current with time as shown in Figure 2E until the electric field effect is lost. At this point, a practically finite thickness is reached that mainly depends on the anodization voltage. The presence of $\mathrm{F}^{-}$strongly affects the anodization and self-ordering of $\mathrm{TiO}_{2}$ nanotubular arrays. If the fluoride concentration is very low, normally $\leq 0.05 \mathrm{wt} \%$, a stable compact $\mathrm{TiO}_{2}$ layer is formed after anodization. Meanwhile, a high fluoride content ( $\geq 1.5 \mathrm{wt} \%$ ) stalls the oxide formation, as all the $\mathrm{Ti}^{4+}$ formed immediately reacts with the drastic amount of fluoride to form soluble $\left[\mathrm{TiF}_{6}\right]^{2-}$, which is similar to an electropolishing process. ${ }^{39}$ For fluoride content within the intermediate level, 0.05-1.5 wt $\%$, a competition between $\mathrm{TiO}_{2}$ formation and dissolution takes place and nanotubular arrays' formation can be observed..$^{31,36,38}$ Since the dissolution of $\mathrm{TiO}_{2}$ highly depends on fluoride concentration, the elevation of fluoride content in the anodization electrolyte can lead to a longer tube with larger diameter.
When the anodization of $\mathrm{Ti}$ is carried out in aqueous electrolyte, most of the composition of fluoride species is in $\mathrm{HF}$ form. In acidic conditions such as $\mathrm{H}_{3} \mathrm{PO}_{4}$ and $\mathrm{H}_{2} \mathrm{SO}_{4}$, a maximum length of $\sim 500 \mathrm{~nm}(\sim 140 \mathrm{~nm}$ in diameter $)$ $\mathrm{TiO}_{2}$ nanotubular arrays can be obtained under optimum conditions (Figure 3A). ${ }^{32}$ Longer nanotubular arrays $(>1 \mu \mathrm{m})$ can be formed in buffered aqueous electrolyte $\left[\left(\mathrm{NH}_{4}\right)_{2} \mathrm{SO}_{4}+\right.$ $\mathrm{NH}_{4} \mathrm{~F}$ and $\left.\mathrm{Na}_{2} \mathrm{SO}_{4}+\mathrm{NaF}\right]$ (Figure 3B). ${ }^{33}$ Such neutral or near neutral electrolyte has less acidity with less dissolution capability on $\mathrm{TiO}_{2} ; \mathrm{TiO}_{2}$ nanotubes with diameters of about $200 \mathrm{~nm}$ can grow up to $4 \mu \mathrm{m}$ under some optimum conditions. Another strategy to carry out the anodization of Ti in non-aqueous electrolyte leads to a significant difference in morphology of as-formed $\mathrm{TiO}_{2}$ nanotubes compared with nanotubes grown in aqueous electrolytes. Since organic electrolytes, such as ethylene glycol, glycerol, dimethyl sulfoxide (DMSO), and ionic liquids, contain a small amount of oxygen, the oxide chemical dissolution in these electrolytes heavily depends on the water concentration. Owing to the low water content, very long (up to $1 \mathrm{~mm}$ ) $\mathrm{TiO}_{2}$ nanotubes with large diameters (up to $700 \mathrm{~nm}$ ) can be obtained (Figures $3 \mathrm{C}^{34}$ and $3 \mathrm{D}^{35}$ ). The different morphologies of the $\mathrm{TiO}_{2}$ nanotubes formed in aqueous and non-aqueous electrolytes can be ascribed, to a large extent, to the low conductivity of non-aqueous electrolytes, and IR-drop effects both decrease the effective voltage of the electrode. ${ }^{31,36}$ The conductivity of the electrolyte changes as the reaction products are formed with the extension of the anodization time, resulting in thicker nanotubes with larger diameters.

If the other electrochemical parameters are kept constant, the duration of the anodization process, which can also be converted to the charge passed during the anodization, controls the nanotubular layer thickness. The thickness of the nanotubes linearly depends on the anodization time (Figure 3E). ${ }^{33,36,56,69-71}$ However, this only holds for a certain amount of time. Due to the etching of $\mathrm{TiO}_{2}$ by the fluoride species in the electrolyte, an equilibrium state between the growth of the nanotubes at the bottom and chemical/electrochemical dissolution of nanotubes at the top will be reached, which is commonly defined as a steady-state condition. At steady-state condition, no further increase in the nanotubular thickness is observed. If anodization is carried out for extended periods of time, nanotubular walls are thinned out and perforated, and the tube tops become decorated with tube wall remnants. Since the oxide growth and chemical dissolution of nanotubes highly depend on the water content in the anodization culture, the amount of water is another factor influencing the nanotube formation. ${ }^{31,36,38}$ A striking effect of the water content is that smooth nanotubular walls are obtained in low water-containing 

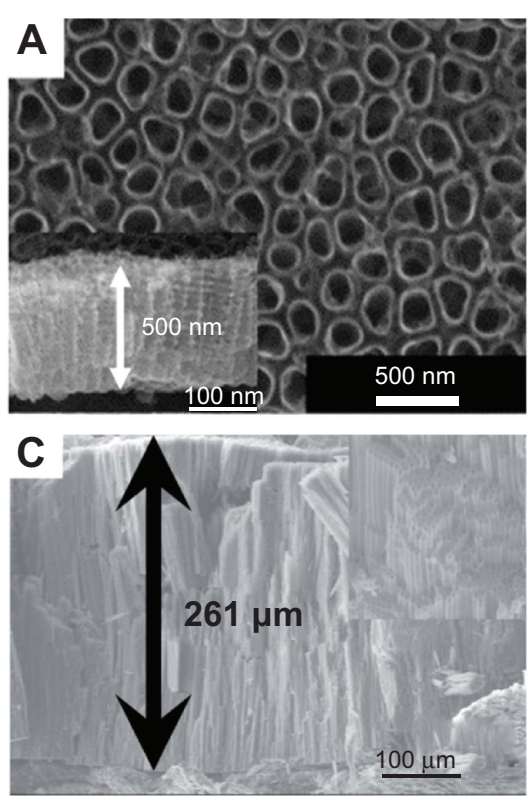
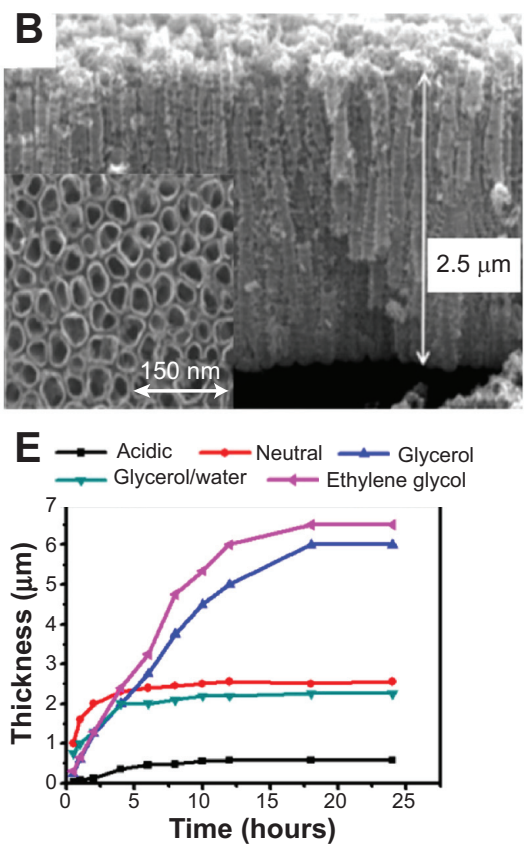

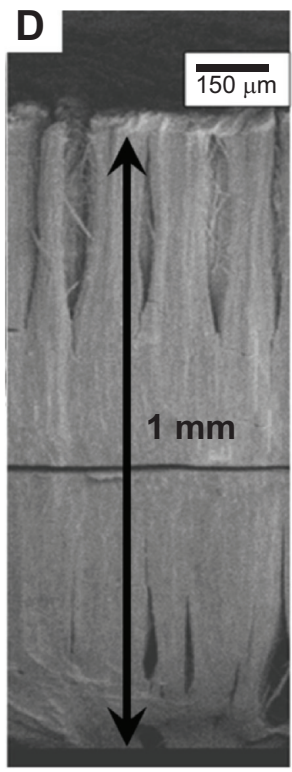

Figure 3 Examples of $\mathrm{TiO}_{2}$ nanotubular arrays obtained by electrochemical anodization in different electrolytes.

Notes: $(A) \mathrm{HF} / \mathrm{H}_{2} \mathrm{SO}_{4}$ solution (anodization voltage at $20 \mathrm{~V}$ ). (B) $\left(\mathrm{NH}_{4}\right)_{2} \mathrm{SO}_{4}+\mathrm{NH}_{4} \mathrm{~F}$ solution (anodization voltage at $20 \mathrm{~V}$. (C) $0.2 \mathrm{M} \mathrm{HF}$ solution (anodization voltage at $120 \mathrm{~V}$ ) and $(\mathbf{D})$ mixed 0.6 weight\% $\mathrm{NH}_{4} \mathrm{~F}$ and ethylene glycerol solution (anodization voltage at $60 \mathrm{~V}$ ). (E) TiO $\mathrm{T}_{2}$ nanotube-layer thickness with anodization times for different electrolytes (anodization voltage for ethylene glycol electrolyte held at $60 \mathrm{~V}$, and $40 \mathrm{~V}$ for other electrolytes). (A) Copyright (C) 2006 with permission from Elsevier. Reprinted from Bauer S, Kleber S, Schmuki P. TiO nanotubes: Tailoring the geometry in $\mathrm{H}_{3} \mathrm{PO}_{4} / \mathrm{HF}$ electrolytes. Electrochem Commun. 2006;8(8): I32I-I325. ${ }^{32}$ (B) Copyright WileyVCH Verlag GmbH \& Co. KGaA. (C) 2005. Reproduced with permission, from Macák JM, Tsuchiya H, Schmuki P. High-aspect-ratio TiO 2 nanotubes by anodization of titanium. Angew Chem Int Ed Engl. 2005;44(14): 2100-2102. ${ }^{33}$ (C) Copyright @ 2007 Wiley-VCH Verlag GmbH \& Co. KGaA. Reproduced with permission, from Albu SP, Ghicov A, Macak JM, Schmuki P. $250 \mu \mathrm{m}$ long anodic TiO, nanotubes with hexagonal self-ordering. Phys Status Solidi Rapid Res Lett. 2007;I(2):R65-R67.34 (D) Copyright (C) 2007, American Chemical Society. Reprinted with permission, from Paulose M, Prakasam HE, Varghese OK, et al. TiO 2 Nanotube Arrays of 1000 mm Length by Anodization of Titanium Foil: Phenol Red Diffusion. J Phys Chem C. 2007; I I I (4I):I4992-14997.35 (E) Copyright Wiley-VCH Verlag GmbH \& Co. KGaA. C 2005. Adapted with permission, from Macák JM, Tsuchiya H, Schmuki P. High-aspect-ratio $\mathrm{TiO}_{2}$ nanotubes by anodization of titanium. Angew Chem Int Ed Engl. 2005;44(I4): 2 I00-2I02.33 Copyright WileyVCH Verlag GmbH \& Co. KGaA. @ 20I I. Adapted with permission, from Roy P, Berger S, Schmuki P. TiO ${ }_{2}$ Nanotubes: Synthesis and Applications. Angew Chem Int Ed Engl. 20I I;50(I3):2904-2939.36 Copyright Wiley-VCH Verlag GmbH \& Co. KGaA. @ 2005. Adapted with permission, from Macak JM, Tsuchiya H, Taveira L, Aldabergerova S, Schmuki P. Smooth anodic $\mathrm{TiO}_{2}$ nanotubes. Angew Chem Int Ed. 2005;44:7463-7465.99 Copyright @ 2008, with permission of Elsevier. Adapted from Macak JM, Hildebrand H, Marten-Jahns U, Schmuki P. Mechanistic aspects and growth of large diameter self-organized $\mathrm{TiO}_{2}$ nanotubes. J Electroanal Chem. 2008;621:254-266. ${ }^{70}$

electrolyte while side wall ripples are formed in higher water contents. ${ }^{38}$ The reason for this effect is that for higher water contents, the fluoride rich layer between the nanotubes shows a faster chemical dissolution rate than the growth rate of the nanotubes into the underlying substrate, ie, ripples at the walls of the nanotubes can be ascribed to the continuous etching and passivation of the cell boundary regions.

\section{Oxide nanotubular arrays on Ti alloys and other metals}

The principle used to grow oxide nanotubular arrays on Ti by using electrochemical anodization technique in fluoride containing electrolyte can be transferred to biocompatible $\mathrm{Ti}$ alloys (shown in Figure 4). Self-organized oxide nanotubular layers have been reported on binary alloys, such as $\mathrm{Ti}-\mathrm{Zr}$, Ti-Ta, Ti-Nb, and Ti-Mo, ternary alloys, such as Ti-6Al-7Nb, Ti-6Al-4V and Ti-35Nb-5Zr, etc, and more complex alloy systems such as Ti-29Nb-13Ta-4.6Zr. ${ }^{36,38,48,50}$ The addition of different elements in Ti alloys drastically affects the anodization process and the ultimate oxide nanotubular morphology and composition. In general, after alloy anodization, the composition of the oxide layer is consistent with the ratio in the alloy. For instance, the anodic oxide nanotubular layers on Ti-Al alloys are composed of $\mathrm{TiO}_{2}$ and $\mathrm{Al}_{2} \mathrm{O}_{3} \cdot{ }^{36}$ The fraction of these two kinds of oxides is the respective fraction of Ti and $\mathrm{Al}$ in the base alloys. With the increase in Ti content of Ti-Al alloy, $\mathrm{TiO}_{2}$ and $\mathrm{Al}_{2} \mathrm{O}_{3}$ nanotubular separation has been observed. Similar phenomena have also been observed on $\mathrm{Ti}-\mathrm{Ta}$ and $\mathrm{Ti}-\mathrm{Nb} .{ }^{50} \mathrm{In}$ some cases, minor amounts of mixed oxides may be present in the anodic nanotubular arrays. A mixed oxide nanotubular structure was reported on Ti-Zr alloys. ${ }^{47}$ Zirconium titanate nanotubular arrays were formed on Ti-50Zr alloys via anodization. ${ }^{47}$

Similar to the $\mathrm{TiO}_{2}$ nanotubular arrays formed on pure $\mathrm{Ti}$, the formation of oxide nanotubular arrays on Ti alloys depends on the anodization parameters including anodic potential, anodization time, $\mathrm{pH}$, and fluoride species concentration, as discussed in the Self ordering of $\mathrm{TiO}_{2}$ nanotubular arrays section. However, due to the different chemical characteristics including selective dissolution of the oxide in fluoride and solubility of the respective metal fluorides in 

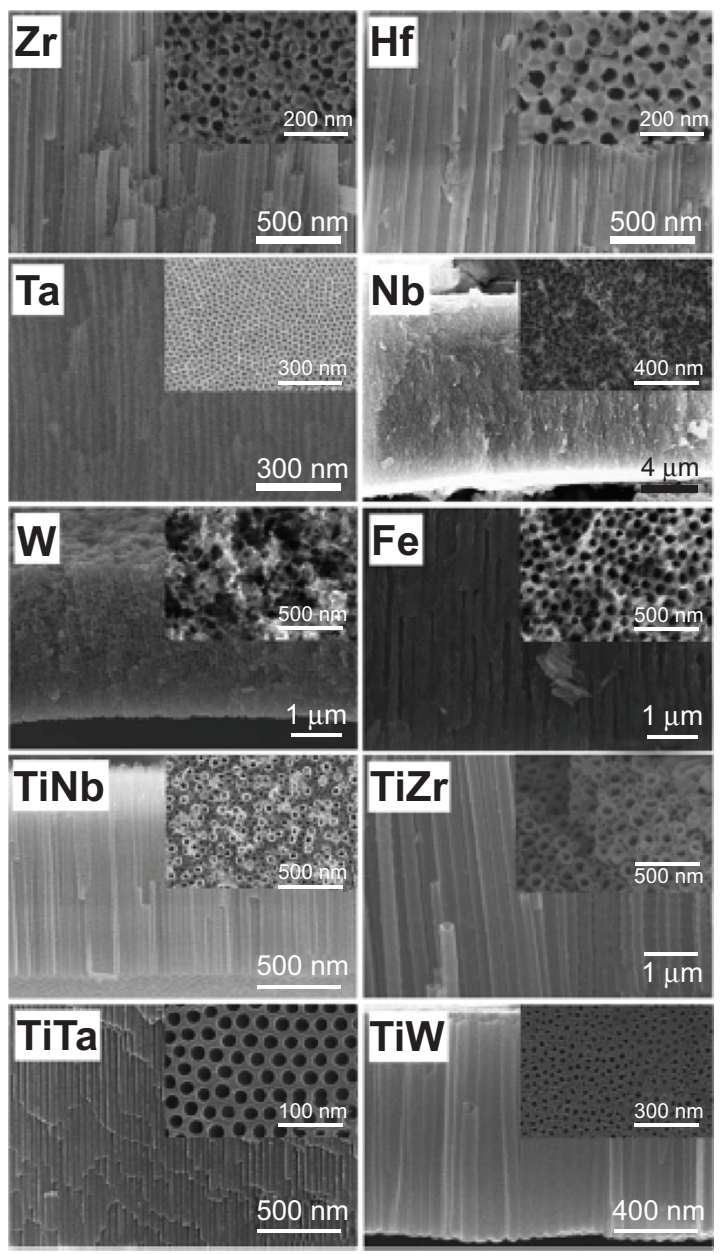

Figure 4 Cross-sectional and top-view SEM images of ordered oxide nanotube or nanopore layers electrochemically grown on different valve metals and metal alloys. Note: Copyright Wiley-VCH Verlag GmbH \& Co. KGaA. (C) 20II. Reproduced with permission from Roy P, Berger S, Schmuki P. $\mathrm{TiO}_{2}$ Nanotubes: Synthesis and Applications. Angew Chem Int Ed Engl. 20 I 1;50(I 3):2904-2939. ${ }^{36}$

Abbreviation: SEM, scanning electron microscope.

different cultures during anodization, the morphology and geometry of oxide nanotubular arrays formed on $\mathrm{Ti}$ alloys are somewhat different from those of the $\mathrm{TiO}_{2}$ nanotubular arrays on pure Ti. In the case of Ti-Ta alloys, the anodization process led to the formation of nanoporous oxide layers first and then dissolution, followed by the formation of nanotubular arrays. For a ternary alloy such as Ti-6Al-4V, both $\alpha$ and $\beta$ phases of Ti were present after the addition of the other element. ${ }^{72}$ Ordered nanotubular arrays were observed on $\alpha$ phase and a mixture of nanotubular arrays and nanoporous structure was present on a complex $\alpha+\beta$ phase. Due to the easy dissolution of $\mathrm{V}_{2} \mathrm{O}_{5}$ (mainly in $\beta$ phase) in fluoride containing culture, the entire $\beta$ phase was easy to be attacked and dissolved until the etching reached the underlying $\alpha$ phase, where a nanotubular structure formed. This very interesting phenomenon was observed on the anodic nanotubular arrays on Ti-Zr-Nb alloys. ${ }^{48}$ Two distinct tube diameters were formed with one large center tube surrounded by smaller tubes, repeated over the entire anodized area. ${ }^{48}$ The tubes had the identical length and showed the same degree of self-ordering, which was ascribed to the availability of current at the different tips. Minagar et al reviewed the effect of $\beta$ stabilizers (eg, $\mathrm{Zr}, \mathrm{Nb}$, and Ta) on the formation of nanotubular arrays on Ti alloys. ${ }^{73,74}$ It was found that by adjusting the $\mathrm{pH}$ value and the chemical composition of the electrolyte, nanotubular arrays with homogeneous open diameters could be fabricated on Ti alloys under certain optimum conditions. Nevertheless, the phenomenon is still not well understood and necessitates extensive work to uncover the formation mechanism.

Depending on the exact electrochemical conditions, selfordered nanotubular/nanoporous layers were also reported for several other metals, such as $\mathrm{Zr},{ }^{43} \mathrm{Hf},{ }^{53} \mathrm{Ta},{ }^{52} \mathrm{Nb},{ }^{54} \mathrm{~W},{ }^{38}$ $\mathrm{Fe},{ }^{31}$ and $\mathrm{Mg}$ (Figure 4). ${ }^{55}$ For each case, some optimization of the electrochemical conditions specific to that element is desired to obtain organized high-aspect-ratio nanotubular structures. Lee et $\mathrm{al}^{51}$ and Tsuchiya et $\mathrm{al}^{75}$ were the first two groups of researchers to have reported on the fabrication of self-ordered $\mathrm{ZrO}_{2}$ nanotubular arrays in fluoride containing species by electrochemical anodization. The formation mechanism of the nanotubular arrays has been described in detail with regards to the effect of changing the concentration of F-, $\mathrm{pH}$ value, the composition of the electrolyte and the applied potential. It was shown that by using organic electrolytes, significantly thick and smooth $\mathrm{ZrO}_{2}$ nanotubular arrays up to $200 \mu \mathrm{m}$ were obtained under a $40 \mathrm{~V}$ stimulated potential. ${ }^{43}$ Irregular $\mathrm{ZrO}_{2}$ nanotubular arrays were obtained by one-step anodization without any pretreatment, owing to the existence of impurities such as carbide in $\mathrm{Zr}$ and the inhomogeneity of the surface. In order to obtain highly ordered nanotubes, pretreatments were applied on $\mathrm{Zr}$ to enhance the self-ordering. Dip-etching, two-step anodizing and electropolishing were applied on $\mathrm{Zr}$ substrate in achieving highly self-ordered $\mathrm{ZrO}_{2}$ nanotubular arrays. ${ }^{76}$ The removal of the impurities along with the electropolishing, which reduced the surface roughness, had an influence on the homogeneous electric field distribution over the entire metal surface during the anodization; thus, self-ordering nanotubular arrays grew regularly on the entire surface. Similarly, high-aspectratio hafnium oxide nanotubular arrays can be achieved under a wide range of anodization parameters. ${ }^{48}$ Tantalum is extremely corrosion resistant in the acidic environments. Thus, extreme conditions are required to obtain nanotubular structures. It was reported that $\mathrm{Ta}_{2} \mathrm{O}_{5}$ nanotubular arrays were formed in a mixed $\mathrm{H}_{2} \mathrm{SO}_{4}$ and $\mathrm{HF}$ electrolyte with up to $1 \mathrm{wt} \% \mathrm{H}_{2} \mathrm{O}$ under the anodization voltage range of 
10-20 V with the anodization times between 5 seconds to 120 seconds. ${ }^{52}$ Extension of the anodization process resulted in the destruction of the nanotubular arrays and dimples on the Ta substrate. The reason for the destruction of nanotubular arrays from the surface was shown to be the formation of a thin, fluoride-rich layer built up at the $\mathrm{Ta} / \mathrm{Ta}_{2} \mathrm{O}_{5}$ interface. ${ }^{52}$ Controversially, for other valve metals such as $\mathrm{Nb}$ and $\mathrm{W}$, still no highly ordered structures but only comparably short nanotubular ones have been reported. ${ }^{38}$ For some non-valve metals like $\mathrm{Fe}^{31}$ and $\mathrm{Mg},{ }^{55}$ high-aspect-ratio oxide nanoporous structure and oxide-fluoride nanotubular structure were recently reported. The reasons for this different behavior may be ascribed to the solubility of a formed oxide structure in the anodizing electrolyte, the solubility of the fluoride species, and the stress generated when the oxide is formed.

In general, all investigated self-ordering oxide structures fabricated by electrochemical anodization in fluoride-containing electrolytes on different metals and alloys seem to follow the same growth principles and key factors for fabrication of $\mathrm{TiO}_{2}$ nanotubular arrays: the diameter of the tubes is determined by the anodization voltage; the tubular length depends on the chemical resistance of the oxide against fluoride etching, which also relates to the anodization voltage, anodization time and the amount of oxygen provided by water for tubular growth.

\section{Biocompatibility approach of metals with nanotubular surfaces Hydroxyapatite formation on nanotubular arrays}

In view of a rapid ingrowth of biomedical implants in bone, a key factor is to quickly stimulate hydroxyapatite (HA) formation from body fluid because HA formation is important for osseointegration. ${ }^{24}$ A number of surface treatments have been explored in order to enhance HA formation on metal implants, eg, the use of different chemical and physical treatments. It is therefore of interest to study metallic oxide nanotubular surfaces in view of HA-induced effects for biocompatibility approach.

The formation of HA on biomedical implants is based on heterogeneous nucleation phenomenon. For a nucleus assuming spherical shape to form in a supersaturated solution, the nucleation rate is ${ }^{27}$

$$
J=A \times \exp \left(\frac{-B}{K T}\right)=A \times \exp \left[\frac{-16 \pi \gamma^{3} v^{2}}{3 \mathrm{~K}^{3} T^{3}(\operatorname{In} S)^{2}}\right],
$$

where $\mathrm{A}$ is the rate coefficient, $\mathrm{B}$ is the activation energy, $\mathrm{K}$ is Boltzmann constant, $\mathrm{T}$ is the temperature, $\gamma$ is the nucleus-solution interfacial energy, $v$ is the molecular volume, and $\mathrm{S}$ is the degree of supersaturation, defined as the concentration product/solubility product (Ksp). If a nucleus forms on a foreign substrate (such as implant materials) at a contact angle of $\theta$, the nucleation rate becomes:

$$
\mathrm{J}^{\prime}=\mathrm{A} \times \exp \left(\frac{-\phi \times \mathrm{B}}{\mathrm{KT}}\right)
$$

and,

$$
\phi=(2+\cos \theta)(1-\cos \theta)^{2} / 4 .
$$

Since $\phi<1, \mathrm{~J}^{\prime}$ in equation (2) is always higher than $\mathrm{J}$ in equation (1). Meanwhile, $\mathrm{J}^{\prime}$ increases with decreasing $\theta$. When $\theta=0$ (spread), the activation energy is also zero and $\mathrm{J}^{\prime}$ reaches a maximum. Therefore, if the solution supersaturation $(\mathrm{S})$ and the substrate condition $(\theta)$ are properly controlled, nucleation and crystallization of HA can preferentially occur on the substrate to form the coating. For example, $\mathrm{TiO}_{2}$ and $\mathrm{ZrO}_{2}$ nanotubular arrays have greater wetting behavior of simulated body fluid (SBF) than flat $\mathrm{Ti}$ and $\mathrm{Zr}$ foils. ${ }^{38,43}$ In addition to surface chemistry, nanotubular arrays change the surface topography at microscale to enhance the nucleation site by largely increasing the surface area. This demonstrates the potential that HA formation can be strongly accelerated on nanotubular surfaces compared with flat metal surfaces.

A very thin layer $(\sim 25 \mathrm{~nm})$ of nanoscale HA phase was introduced on $\mathrm{TiO}_{2}$ nanotubular arrays after immersion in SBF for a week. ${ }^{77}$ However, a pretreatment of $\mathrm{TiO}_{2}$ nanotubular arrays in alkaline solution was required according to some researchers. ${ }^{78}$ Thus, the case might not directly show the benefit of nanotubular arrays for HA formation. Systematic studies on the formation of HA coating on $\mathrm{TiO}_{2}$ nanotubular arrays were first reported by Tsuchiya et al (Figure 5). ${ }^{46}$ In order to obtain a uniform and thick HA coating, it is highly desirable to fabricate nanotubes with larger opening diameters and deeper depth for calcium and phosphorous species' nucleation and growth. To achieve the HA coating by immersing $\mathrm{TiO}_{2}$ nanotubular arrays into SBF, a minimum opening diameter of $15 \mathrm{~nm}$ is required. ${ }^{46}$ Several studies have confirmed that at least 14 days were required to obtain an HA coating of over 1 micrometer thick on $\mathrm{TiO}_{2}$ nanotubular arrays, as compared to no coating formation on flat $\mathrm{Ti}^{4}{ }^{46}$ Additionally, the $\mathrm{TiO}_{2}$ crystallinity (anatase/rutile) also influenced the HA coating formation. A mixture of anatase and rutile $\mathrm{TiO}_{2}$ nanotubular arrays showed an enhancement of HA formation rate of at least 2 -fold. ${ }^{46}$ Moreover, the advantageous 3D structure of 
Compact layer
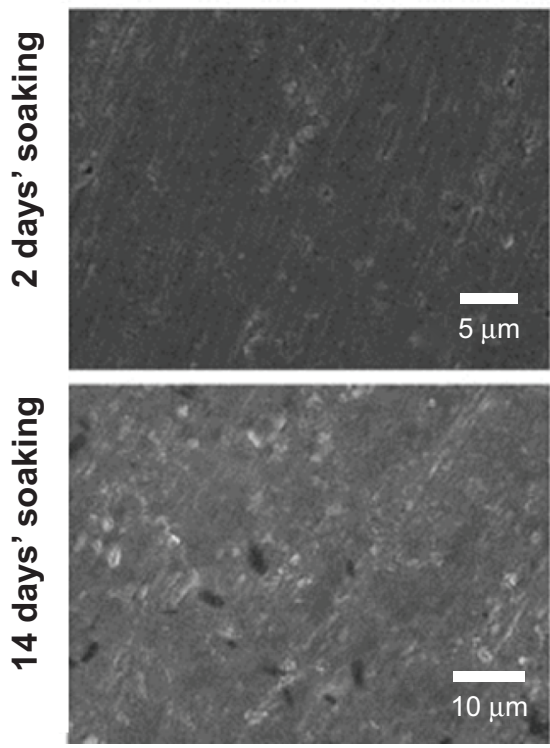

Short-nanotube layer
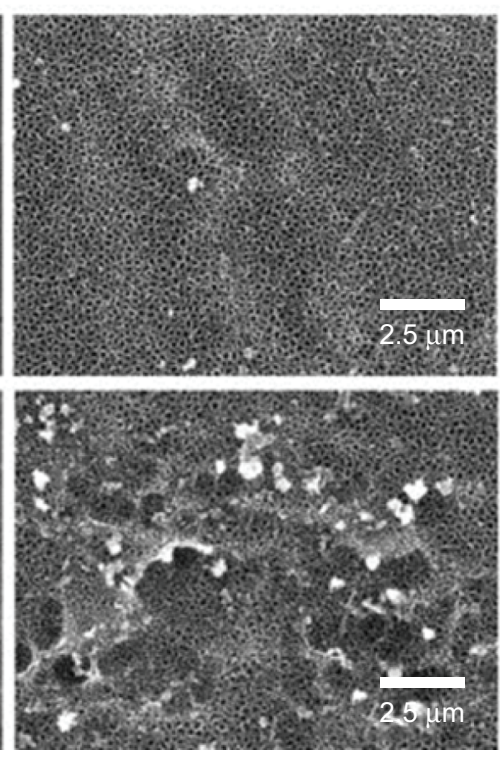

Long-nanotube layer
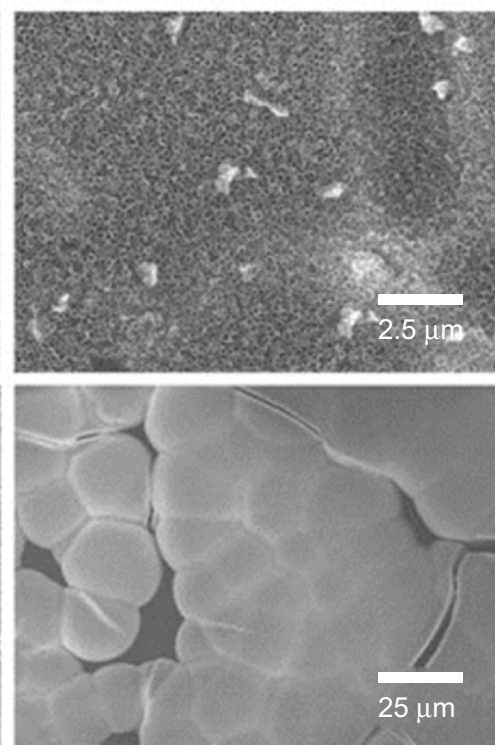

Figure 5 SEM images of the as-prepared amorphous $\mathrm{TiO}_{2}$ layers after soaking in SBF for different periods.

Notes: Compared at the compact layer ( $50 \mathrm{~nm}$ thick) $\mathrm{TiO}_{2}$ layer, the $500 \mathrm{~nm}$ nanotubes and the 2 um long nanotubes. Copyright Wiley-VCH Verlag GmbH \& Co. KGaA. (C) 2006. Reproduced with permission from Tsuchiya H, Macak JM, Taveira L, Ghicov A, Schmuki P. Hydroxyapatite growth on anodic TiO, nanotubes. J Biomed Mater Res. 2006;77(3):534-54I.46

Abbreviations: SBF, simulated body fluid; SEM, scanning electron microscope.

nanotubular arrays is optimal for embedding precursors for HA formation, which additionally promotes HA nucleation and accelerates its formation. Several attempts have been carried out to induce amorphous calcium phosphorous particles or nanocrystalline HA in the nanotubular structure by wet chemical methods before the formation of HA in SBF. ${ }^{43}$ These methods highly relied on the size of the nanotubular arrays rather than the tube crystal structure. By applying these methods, the HA formation rate can be enhanced by about 10 -fold. ${ }^{78}$ Another attempt to incorporate anion to enhance the HA formation on nanotubular arrays has been made by Wang et al who created $\mathrm{ZrO}_{2}$ nanotubular layers which were incorporated with a large amount of phosphorous anions by anodization in phosphorous species containing electrolyte. By immersing such nanotubular arrays in SBF, the phosphorous anions can adsorb $\mathrm{Ca}^{2+}$ to precipitate and form HA coatings within only 4 days. The incorporation of anions in electrolytes demonstrates a potential to modify the nanotubular arrays with designated species for a particular application. ${ }^{79}$

\section{In vitro and in vivo studies of metallic oxide nanotubular arrays}

Cytocompatibility leads to promoted bone integration and growth on implants. It is therefore worth studying the responses of living matter and biologically relevant species, such as bone cells, to nanotubular layers on metallic implants.
The most widely used cell types for studies of bioactivity of nanotubular arrays are osteoblasts (bone cells), fibroblasts (connective tissue cells), bone marrow cells, and stem cells (pluripotent undifferentiated cells). ${ }^{30}$ It is therefore a spectacular interaction of living cells with nanotubular layers. A pioneering work on cell interactions with $\mathrm{TiO}_{2}$ nanotubular arrays reported by Park et al in 2007 showed that mesenchymal stem cells reacted in a very pronounced way to the diameter of nanotubes. ${ }^{80}$ The vitality of the cells was significantly increased on nanotubes as compared with flat metals. Diameters of $\sim 15 \mathrm{~nm} \mathrm{TiO}_{2}$ and $\mathrm{ZrO}_{2}$ strongly promote cells' adhesion, proliferation, and differentiation. ${ }^{81}$ Nanotubes with diameters greater than $50 \mathrm{~nm}$ were found to be detrimental on cells' vitality, inducing programmed cell death (shown in Figure 6). ${ }^{81}$ This effect may be related to the effective sizescale of the integrin-based focal contact formation between cells and nanotubular surfaces, and the optimum nanotube diameter seems to enhance cellular activities compared to smooth surfaces. In several conflicting cases, however, osteoblast cells respond to and proliferate on $\mathrm{TiO}_{2}$ nanotubes greater than $100 \mathrm{~nm} .{ }^{82}$ Other than the size effect, crystallinity of nanotubular arrays, remaining fluoride concentration, and surface pretreatment also affected the cell activity. It was shown that anatase/rutile $\mathrm{TiO}_{2}$ slightly enhanced the proliferation of cell activities in short term (1 day) in vitro cell culture test. Immersion of as-formed nanotubular arrays in alkaline solution greatly decreases the remaining fluoride 
A

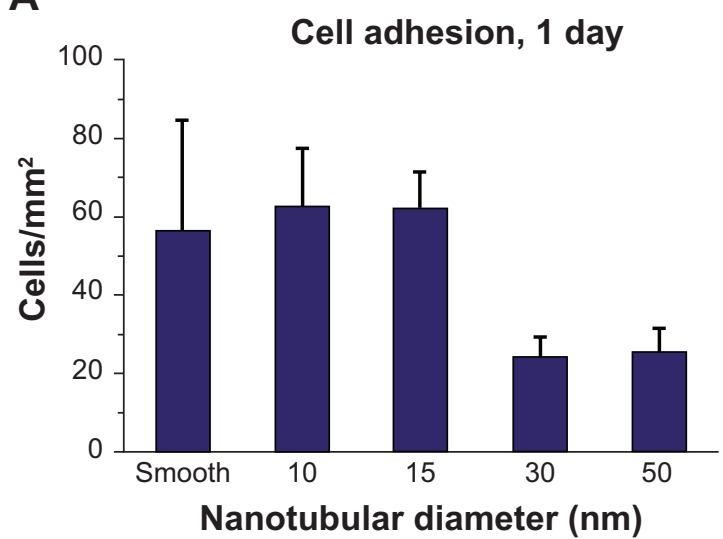

B

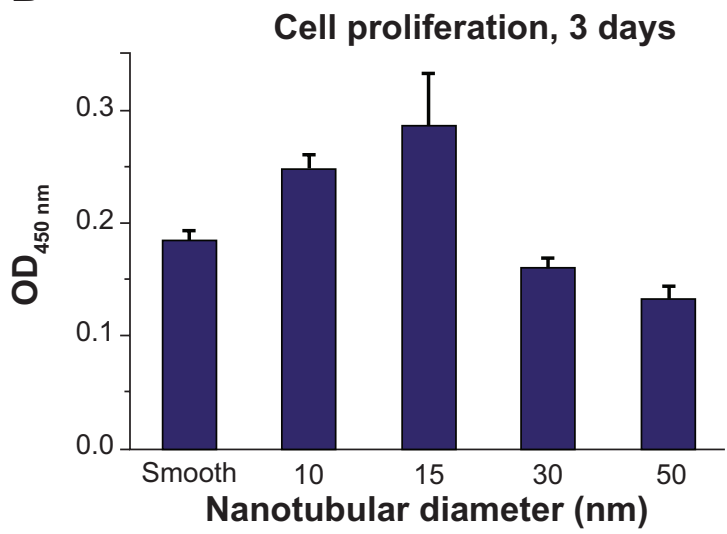

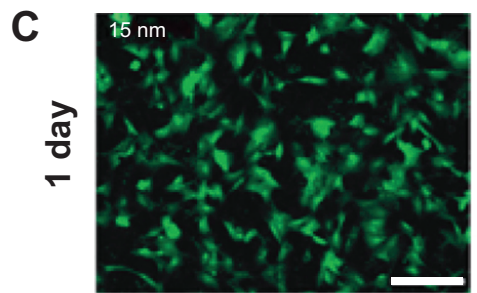
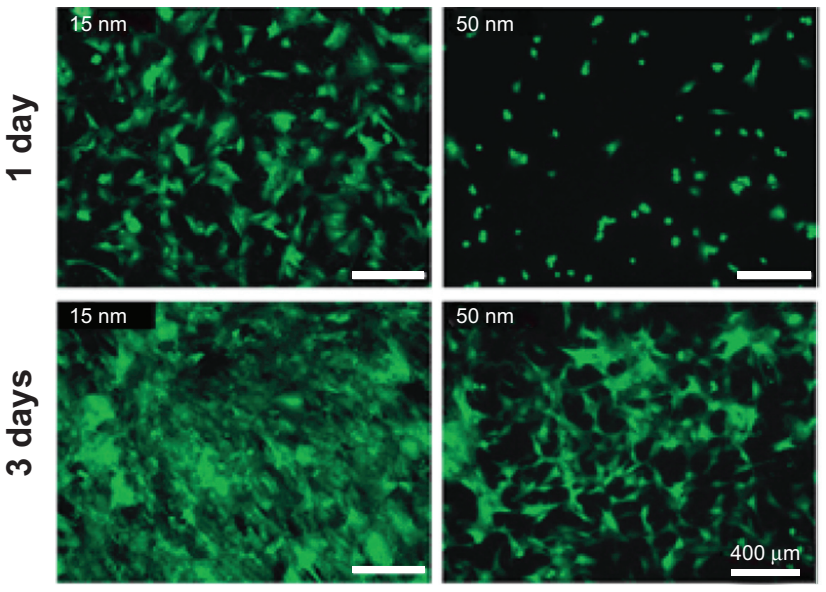

Figure 6 Cell densities of adherent cells on $\mathrm{ZrO}_{2}$ nanotubes with different diameter count under fluorescence microscope after 24 hours' adhesion (A) and measured using colorimetric WST-assay after 3 days' proliferation (B). Fluorescence images of GFP-labeled mesenchymal stem cells after 24 hours' adhesion and 3 days' proliferation (C). Note: Copyright (C) 2009. Reproduced by permission of the Royal Society of Chemistry, from Bauer S, Park J, Faltenbacher J, Berger S, von der Mark K, Schmuki P. Size selective behavior of mesenchymal stem cells on $\mathrm{ZrO}_{2}$ and $\mathrm{TiO}_{2}$ nanotube arrays. Integr Biol (Camb). 2009; I (8-9):525-532. ${ }^{81}$

Abbreviations: GFP, green fluorescence protein; OD, optical density; WST, water soluble tetrazolium salts.

species and results in an appropriate chemical culture for cell proliferation. Additionally, deposition of nanoscale Au particles in $\mathrm{TiO}_{2}$ and $\mathrm{ZrO}_{2}$ nanotubular arrays enhanced the mesenchymal stem cells' attachment. ${ }^{81}$ However, most of the work has clearly demonstrated that the effect of size of nanotubular arrays dominates over tubular crystal structure, fluoride content, and other surface pretreatment. ${ }^{36}$ Moreover, some researchers studied the mechanism of enhancement of bone cell function on $\mathrm{TiO}_{2}$ nanotubular structure. ${ }^{38}$ Two kinds of proteins, fibronectin and vitronectin, are major proteins involved in osteoblast adhesion. The obtained results indicated the significantly increased fibronectin $(15 \%)$ and vitronectin $(18 \%)$ adsorption on nanotubular structures compared to flat Ti samples. Since the cells adhered to the metal surface via pre-adsorbed proteins, the increased fibronectin and vitronectin adsorption on $\mathrm{TiO}_{2}$ nanotubular structures might explain the observed enhancement of the osteoblast functions. ${ }^{83}$

Recently, several research groups demonstrated that surface functionalization and surface chemistry can further improve the benefits of metal oxide nanotubular arrays with regards to cytocompatibility. In one study, the surface of $\mathrm{TiO}_{2}$ nanotubular arrays was modified by bone morphogenetic protein 2 (BMP2) and it was found that BMP2modified surfaces were beneficial for mesenchymal stem cell proliferation, with significantly enhanced differentiation levels compared to unmodified nanotubes. ${ }^{84}$ Another study reported by Bauer et al indicated that changing the wettability of the nanotubular surface from superhydrophilic to superhydrophobic altered the adsorption of extracellular matrix proteins such as fibronectin, collage type I, laminin, and bovine serum albumin, and improved the attachment of mesenchymal stem cells. ${ }^{85}$ The same group applied epidermal growth factor (EGF) to modify $\mathrm{TiO}_{2}$ nanotubular arrays with different diameters and they found the EGF-coated surface significantly improved cell activity and cell number on nanotubes with a diameter of $100 \mathrm{~nm} .{ }^{86}$ Other than protein and growth factors, inorganic species, such as carbon, were also applied to modify metallic oxide nanotubular arrays. 
Brammer et al reported that carbon coated $\mathrm{TiO}_{2}$ nanotubes enhance mesenchymal stem cell differentiation over $\mathrm{TiO}_{2}$ nanotubes. ${ }^{87}$ Interestingly, several potential orthopedic non-metal materials (specifically, polyetheretherketone, ultra-high molecular weight polyethylene, and polytetrafluoroethylene) were coated with Ti using a novel ionic plasma deposition process that created a surface-engineered nanostructure (with features below $100 \mathrm{~nm}$ ). ${ }^{88}$ The result was improved osteoblast adhesion over flat $\mathrm{Ti}$ and uncoated polymers. To date, a large part of the interest has remained on modifying the existing $\mathrm{TiO}_{2}$ and some on $\mathrm{ZrO}_{2}$ nanotubes; however, little notice has been given to tantalum oxide $\left(\mathrm{Ta}_{2} \mathrm{O}_{5}\right)$ nanotubes, which are formed via a similar self-assembly mechanism to $\mathrm{TiO}_{2} / \mathrm{ZrO}_{2}$ nanotubes, via electrochemical anodization. Tantalum is also one kind of valve metal which possesses a thin passivation oxide layer which makes it highly resistant to corrosion caused by bodily fluids. It was found that osteoblast and mesenchymal stem cell growth and vitality were also enhanced on $\mathrm{Ta}_{2} \mathrm{O}_{5}$ nanotubes compared to flat Ta. ${ }^{89}$

Von Wilmowsky et al reported the first work on evaluation of the bioactivity of nanotubular arrays in vivo (Figure 6A and $6 \mathrm{~B}){ }^{44}$ Tests on adult pigs showed that Ti implants with a nanotubular structure surface do influence bone formation and bone development by enhancing osteoblast function. The tests also concluded that higher implant-bone contact can be established if implants are coated with nanotubular arrays. Additionally, these nanotubular coatings also resisted shearing forces evoked by implant insertion, an unexpected advantage of nanotubular arrays on implant surfaces. However, in terms of a complex culture in vivo, some authors pointed out that negative effects of nanotubular arrays may also be exploited on surfaces when cell proliferation is not desired. ${ }^{36}$

\section{Nanotubular arrays for drug delivery and other preload applications}

The 3D geometry of the metallic oxide nanotubular arrays indicates that the materials are appropriate carriers for drugdelivery capsules and drug-eluding coatings on biomedical implant materials. ${ }^{31}$ For bone healing and regeneration, genes and proteins could be loaded in metallic oxide nanotubes and delivered to promote osteoblast bone forming ability, mesenchymal stem cell osteogenesis, and mineral formation. Several research groups have reported the study of long-term small molecule and protein release for up to 1 month from $\mathrm{TiO}_{2}$ nanotubes. ${ }^{90-94}$ It was also found that loading the nanotubes with antibiotics significantly increased the osteoblast functionality. ${ }^{94}$ Varying the nanotubular geometry, such as diameter, wall thickness and length can alter the release kinetics for each specific drug to achieve a sustained release. ${ }^{92} \mathrm{TiO}_{2}$ nanotube arrays with $110 \mathrm{~nm}$ diameter have been used as nanoscale reservoirs for growth factor (BMP2) using gelatin/chitosan (Gel/Chi) multilayers to control the release of the functional molecule and maintain its bioactivity. ${ }^{95}$ The arrays displayed great potential for retaining the bioactivity of the drug and regulating the motility and differentiation of mesenchymal stem cells. ${ }^{95} \mathrm{On}$ the other hand, although nanotubular configuration has been studied in depth for potential biomedical and drug delivery type applications, 10-20 nm spacing between neighboring nanotubes provides increased volume and surface area. A potential in vivo capsule in terms of $\mathrm{TiO}_{2}$ nanotubular arrays has been designed by von Wilmowsky et $\mathrm{al}^{44}$ and Shrestha et $\mathrm{al}^{196}$ (Figure $7 \mathrm{C}$ ). The drug with long molecules can be attached to $\mathrm{TiO}_{2}$ surfaces by wet chemical methods. The nanotubes are filled by magnetic $\mathrm{Fe}_{3} \mathrm{O}_{4}$ particles before the attachment of drugs, and these tubes can be magnetically guided to a designated location. Drugs can be released photocatalytically via ultraviolet reactions.${ }^{97}$ Additionally, drugs can also be released by electronically stimulated catalysis and more importantly by X-rays, which allows in vivo treatment through living tissue. Such $\mathrm{TiO}_{2}$ can be used directly for photocatalytic reactions with cells or tissues, including the site-selective killing of cancer cells. Metal oxide/aqueous interfaces play an important role in the adsorption/desorption of organic payloads. Thus, the wettability of nanotubular arrays was adjusted for different payload filling and release. An amphiphilic $\mathrm{TiO}_{2}$ nanotubular arrays were created composed of hydrophilic drugs and hydrophobic monolayer caps as in vivo capsule. The cap did not allow body fluids to enter into the tubes after implantation in the body unless opened by a photocatalytic interaction. Once the hydrophobic layer was removed, body fluids could enter the tubes and wash out hydrophilic drugs loaded within the tubes. ${ }^{89}$ In order to achieve an appropriate elution time for loadings, some researchers suggested that capping of drug-loaded tubular or mesoporous nanotubular layer with biopolymer might represent an efficient and promising drug-release system. ${ }^{32}$

\section{Conclusion and other aspects}

Cell behavior including proliferation and differentiation, mineral formation, and natural integration with bone are highly affected by implant topography, which is desirable for many regenerative medicine applications. This approach 

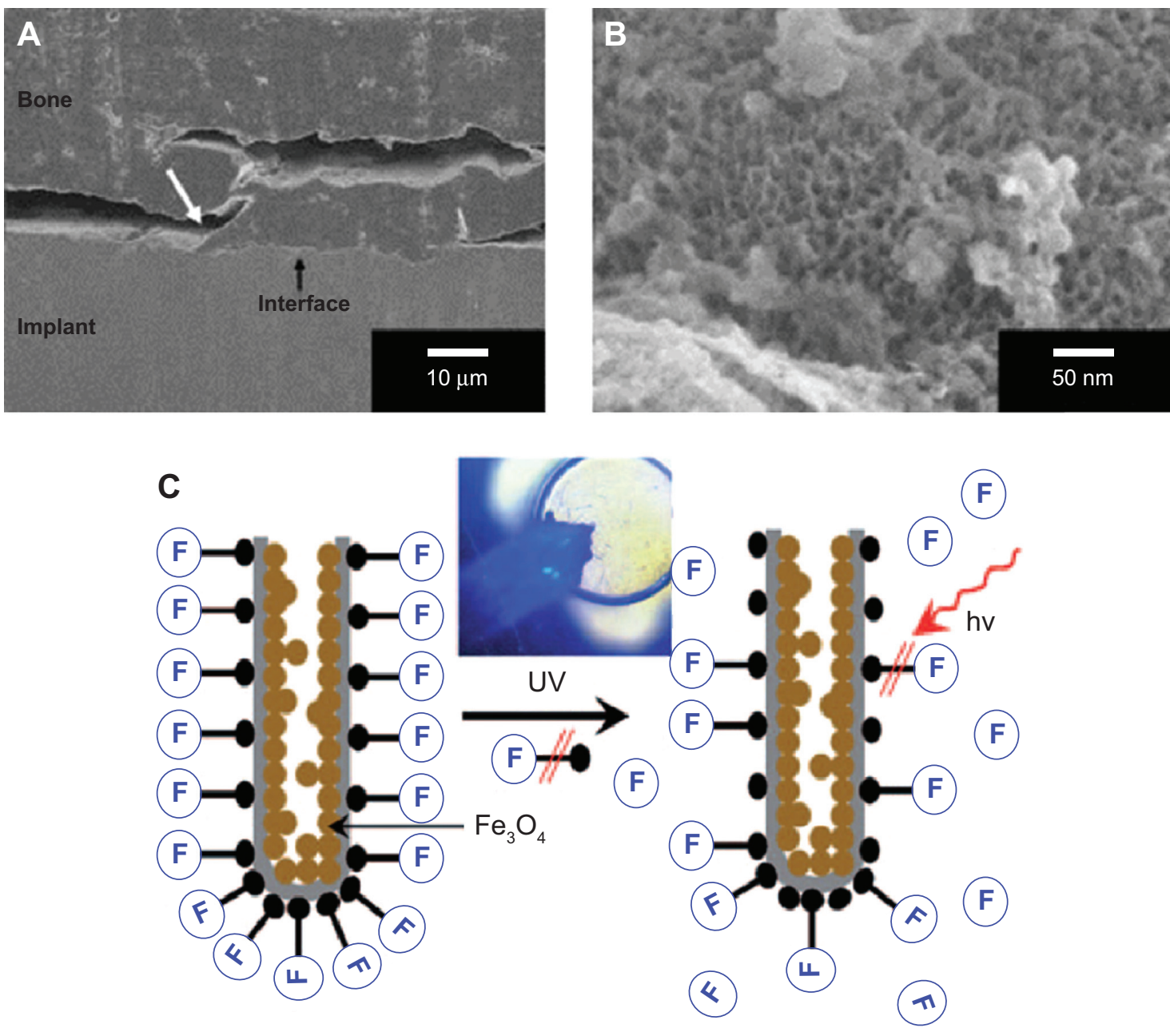

Figure 7 SEM pictures of the histological specimen.

Notes: $(\mathbf{A})$ The interface between the anodic $\mathrm{TiO}_{2}$ nanotube implant and the bone can be seen. A partial breakage of the interface is due to the histological preparation. (B) Magnification reveals that the anodic $\mathrm{TiO}_{2}$ nanotubes keep their structure and do not get damaged by shearing forces due to the implantation process; $(\mathbf{C}) \mathrm{TiO}_{2}$ nanotube for guided drug release: representation of magnetically loaded $\mathrm{TiO}_{2}$ nanotubes with attached drug $(\mathrm{F})$. Release is triggered by photocatalytic chain scission upon UV irradiation. Inset: an example where a blue fluorescent molecule is released from magnetically actuated nanotubes. (A) and (B) Copyright Wiley-VCH Verlag GmbH \& Co. KGaA. (C) 2008. Reproduced with permission from von Wilmowsky C, Bauer S, Lutz R, et al. In vivo evaluation of anodic TiO 2 nanotubes: an experimental study in the pig. J Biomed Mater Res B Appl Biomater. 2009;89(I): I65-I7I.44, (C) Copyright Wiley-VCH Verlag GmbH \& Co. KGaA. C) 2009. Reproduced with permission from Shrestha NK, Macak JM, Schmidt-Stein F, et al. Magnetically guided titania nanotubes for site-selective photocatalysis and drug release. Angew Chem Int Ed Engl. 2009;48(5):969-972. ${ }^{96}$

Abbreviation: SEM, scanning electron microscope.

utilizes the physical properties of nano-structured surfaces to establish a technique to precisely control cell physiology. A highly bioactive surface can be developed, by varying the dimensions or geometry of the nanoscale features, surface functionalities, and chemical properties, to provide a solid and practical foundation of effective implant substrates.

As a surface modification technique, electrochemical anodization could create desired local chemistry and/or topography changes and could be used with other treatments (eg, hydrothermal) synergistically. First, anodization is able to provide a controlled way to create nano-roughness or even nano-features. Generally, there are two mechanisms that are responsible for osseointegration of bone: biomechanical interlocking, and biological interactions. The former depends on the roughness and surface irregularity. Current femoral stems made of valve metals or alloys (eg, $\mathrm{Ti}$ and $\mathrm{Ti}$ alloys) are usually macro-textured to provide such surface features for bone to mechanically interlock. Biological interactions, on the other hand, involve more complex systems. In consideration of roughness in different scales, it was reported that increased micro/submicron roughness could enhance bone cell function, such as alkaline phosphatase activity, while some other studies have revealed the enhanced cell-implant interactions on nanoporous or nanophase materials. It is thus proposed that the future Ti implant should possess roughness in a mixed microscale and nanoscale. One possible approach to accomplish this is by subjecting implants to techniques such as polishing and mechanical 
grinding that promote micro-roughness, followed by a quick anodization process to induce nanotubular structures. Second, HA films produced using nanotubular metallic oxides have shown some advantages over conventional ones. Moreover, HA deposited onto the nanotubular metallic oxides could be at nano-scale in dimension. One problem that still needs to be more fully investigated is the bonding strength between HA crystals and the nanotubular arrays.

On the other hand, there are still questions remaining unanswered for application of oxide nanotubular arrays on metals as implants. An obvious contradiction was that the optimal dimension of the anodized nanotubes varies between different groups. This is why it is particularly beneficial to try to translate the in vitro results to in vivo experiments using animal models and eventually in clinical trials. As mentioned in the in vitro and in vivo studies of metallic oxide nanotubular arrays section, $15 \mathrm{~nm} \mathrm{TiO}_{2}$ nanotubes have been shown to promote optimal growth in vitro but in vivo study in a mini-pig suggested that $70 \mathrm{~nm} \mathrm{TiO}_{2}$ nanotubes were optimal. ${ }^{44,80}$ Another study showed, however, that $100 \mathrm{~nm}$ $\mathrm{TiO}_{2}$ nanotubes enhanced osseointegration in vitro and in vivo over both control and microtopographic surface features in a rabbit tibia. ${ }^{95}$ It is definitely clear that oxide nanotube implants demonstrated a significant enhancement in new bone formation and gene expression associated with bone formation and remodeling over flat surfaces. Nevertheless, all the studies reported that can be utilized to improve and control bone forming functionality for advanced orthopedic implant technologies are still in progress. Clinical studies with anodic metallic oxide nanotubes are also currently lacking with regards to implantation applications. There is significant evidence that stem cells can be seeded into nanotubes for growth and amplification as emphasized in this report and others. ${ }^{98,99}$ This work helps to enable the design of improved nano-surfaces for selective mesenchymal stem cells osteogenesis, thus providing a novel platform for mesenchymal stem cell-based advanced implants.

In summary, electrochemical anodization to fabricate nanoscale surfaces serves as a quick and efficient modification method of metallic implants and has shown significant potential for enhancing the implant's lifetime. There are still vast parameters, such as nanotubular geometry, size, and patterns on substrate, to be optimized for the fabrication of oxide nanotubular arrays on metallic implants for orthopedic applications, especially for bone regeneration. The potential gain of these studies would probably be enormous both in the fundamental understanding of the central processes in cell biology and in the application of a new approach to advance biomaterials and orthopedic implant design.

\section{Acknowledgments}

This work was prepared in conjunction with the project under contract No YETP0419 with the Beijing Higher Education Young Elite Teacher Project, and the Fundamental Research Fund from the University of Science and Technology Beijing. $\mathrm{XL}$ is grateful for the financial support for the project under contract No 2012Z-10 with the State Key Lab of Advanced Metals and Materials, University of Science and Technology Beijing, and No 51204015 with the National Natural Science Foundation of China. JL is grateful for the financial support from Natural Sciences and Engineering Research Council of Canada.

\section{Disclosure}

The authors declare that they alone are responsible for the content and writing of this paper. The authors report no conflicts of interest in this work.

\section{References}

1. 4.5 Million Americans Living with Total Knee Replacement [webpage on the Internet]. Science News line Medicine. Available from: http://www.sciencenewsline.com/articles/2012021012390001.html/. Accessed June 15, 2014

2. Bowlin GL, Wnek G, editors. Encyclopedia of Biomaterials and Biomedical Engineering. New York: Marcel Dekker; New York 2004.

3. Leskinen J, Eskelinen A, Huhtala H, Paavolainen P, Remes V. The incidence of knee arthroplasty for primary osteoarthritis grows rapidly among baby boomers: a population-based study in Finland. Arthritis Rheum. 2012;64(2):423-428.

4. Black J. Biological Performance of Materials: Fundamentals of Biocompatibility. 4th ed. Boca Raton: CRC Press; 2006.

5. Ratner BD, Hoffman AS, Schoen FJ, Lemons JE. Biomaterials Science, An Introduction to Materials in Medicine. 3rd ed. New York: Academic Press; 2012.

6. El-Meliegy E, van Noort R. Glass and Glass Ceramics for Medical Applications. New York: Springer; 2012.

7. Domb AJ, Kumar N, Ezra A. Biodegradable Polymers in Clinical Use and Clinical Development. Hoboken: John Wiley \& Sons; 2011.

8. Wong JY, Bronzino JD, editors. Biomaterials. Boca Raton: CRC Press; 2007.

9. Winters GL, Nutt MJ, editors. Stainless Steels for Medical and Surgical Applications. West Conshohocken: ASTM International; 2003.

10. Rodriguez-González FÁ. Biomaterials in Orthopaedic Surgery. West Conshohocken: ASTM International; 2009.

11. Brunette DM, Tengvall P, Textor M, Thomsen P. Titanium in Medicine. Berlin: Springer; 2001.

12. Oshida Y. Bioscience and Bioengineering of Titanium Materials. Oxford: Elsevier; 2007.

13. Disegi JA, Kennedy RL, Pilliar R, editors. Cobalt-Base Alloys for Biomedical Applications. West Conshohocken: ASTM International; 1999.

14. Zardiackas LD, Kraay MJ, Freese HL, editors. Titanium, Niobium, Zirconium, and Tantalum for Medical and Surgical Applications. West Conshohocken: ASTM International; 2004.

15. Ito A, Okazaki Y, Tateishi T, Ito Y. In vitro biocompatibility, mechanical properties, and corrosion resistance of Ti-Zr-Nb-Ta-Pd and Ti-Sn-NbTa-Pd alloys. J Biomed Mater Res. 1995;29(7):893-899.

16. Lampman S. Wrought Titanium and Titanium Alloys, Properties and Selection: Nonferrous Alloys and Special-Purpose Materials. Materials Park: ASM International; 1990. 
17. Puleo DA, Nanci A. Understanding and controlling the bone-implant interface. Biomaterials. 1999;20(23-24):2311-2321.

18. Zhang Z, Shively JE. Generation of Novel Bone Forming Cells (Monoosteophils) from the Cathelicidin-Derived Peptide LL-37 Treated Monocytes. PLoS ONE. 2010;5:e13985.

19. Albrektsson T, Albrektsson B. Osseointegration of bone implants: A review of an alternative mode of fixation. Acta Orthop Scand. 1987;58(5):567-577.

20. Shalabi MM, Gortemaker A, Van't Hof MA, Jansen JA, Creugers NH. Implant surface roughness and bone healing: a systematic review. J Dent Res. 2006;85(6):496-500.

21. Weiner S, Wagner HD. The material bone: structure-mechanical function relations. Ann Rev Mater Sci. 1998;28:271-298.

22. Rezwan K, Chen QZ, Blaker JJ, Boccaccini AR. Biodegradable and bioactive porous polymer/inorganic composite scaffolds for bone tissue engineering. Biomaterials. 2006;27(18):3413-3431.

23. Mour M, Das D, Winkler T, et al. Advances in Porous Biomaterials for Dental and Orthopaedic Applications. Materials. 2010;3(5): 2947-2974.

24. LeGeros RZ. Calcium phosphate-based osteoinductive materials. Chem Rev. 2008;108(11):4742-4753.

25. Chalasani R, Poole-Warren L, Conway RM, Ben-Nissan B. Porous orbital implants in enucleation: a systematic review. Surv Ophthalmol. 2007;52(2):145-155.

26. Gardin C, Ferroni L, Favero L, et al. Nanostructured biomaterials for tissue engineered bone tissue reconstruction. Int J Mol Sci. 2012;13(1): 737-757.

27. LeGeros RZ. Calcium phosphate materials in restorative dentistry: a review. Adv Dent Res. 1988;2(1):164-180.

28. Ambard AJ, Mueninghoff L. Calcium phosphate cement: review of mechanical and biological properties. J Prosthodont. 2006;15(5): 321-328.

29. Narayan R. The next generation of biomaterial development. Phil Trans R Soc A. 2010;368(1917):1831-1837.

30. Yao C, Webster TJ. Anodization: a promising nano-modification technique of titanium implants for orthopedic applications. J Nanosci Nanotechnol. 2006;6(9):2682-2692.

31. Ghicov A, Schmuki P. Self-ordering electrochemistry: a review on growth and functionality of $\mathrm{TiO}_{2}$ nanotubes and other self-aligned $\mathrm{MO}_{x}$ structures. Chem Commun (Camb). 2009;(20):2791-2808.

32. Bauer S, Kleber S, Schmuki P. $\mathrm{TiO}_{2}$ nanotubes: Tailoring the geometry in $\mathrm{H}_{3} \mathrm{PO}_{4} / \mathrm{HF}$ electrolytes. Electrochem Commun. 2006;8(8): $1321-1325$.

33. Macák JM, Tsuchiya $\mathrm{H}$, Schmuki P. High-aspect-ratio $\mathrm{TiO}_{2}$ nanotubes by anodization of titanium. Angew Chem Int Ed Engl. 2005;44(14): 2100-2102.

34. Albu SP, Ghicov A, Macak JM, Schmuki P. $250 \mu \mathrm{m}$ long anodic $\mathrm{TiO}_{2}$ nanotubes with hexagonal self-ordering. Phys Status Solidi Rapid Res Lett. 2007;1(2):R65-R67.

35. Paulose M, Prakasam HE, Varghese OK, et al. $\mathrm{TiO}_{2}$ Nanotube Arrays of $1000 \mu \mathrm{m}$ Length by Anodization of Titanium Foil: Phenol Red Diffusion. J Phys Chem C. 2007;111(41):14992-14997.

36. Roy P, Berger S, Schmuki P. $\mathrm{TiO}_{2}$ Nanotubes: Synthesis and Applications. Angew Chem Int Ed Engl. 2011;50(13):2904-2939.

37. Ali G, Chen C, Yoo SH, Kim JM, Cho SO. Fabrication of complete titania nanoporous structures via electrochemical anodization of Ti. Nanoscale Res Lett. 2011;6:332-341.

38. Grimes CA, Mor GK. TiO Nanotube Arrays: Synthesis, Properties, and Applications. London: Springer; 2009.

39. Shankar K, Basham JI, Allam NK, et al. Recent Advances in the Use of $\mathrm{TiO}_{2}$ Nanotube and Nanowire Arrays for Oxidative Photoelectrochemistry. J Phys Chem C. 2009;113(16):6327-6359.

40. Zhang Q, Xu H, Yan W. Highly Ordered $\mathrm{TiO}_{2}$ Nanotube Arrays: Recent Advances in Fabrication and Environmental Applications - A Review. Nanosci Nanotechnol Lett. 2012;4(5):505-519.

41. Gong D, Grimes CA, Varghese OK, et al. Titanium oxide nanotube arrays prepared by anodic oxidation. J Mater Res. 2001;16(12):3331-3334.
42. Wang K, Liu G, Hoivik N, Johannessen E, Jakobsen H. Electrochemical engineering of hollow nanoarchitectures: pulse/step anodization (Si, Al, Ti) and their applications. Chem Soc Rev. 2014;43: $1476-1500$.

43. Wang LN. Surface Modification of Zirconium Implants via Electrochemical Anodization and Wet Chemical Techniques. [PhD thesis]. Edmonton: University of Alberta; 2011.

44. von Wilmowsky $\mathrm{C}$, Bauer $\mathrm{S}$, Lutz $\mathrm{R}$, et al. In vivo evaluation of anodic $\mathrm{TiO}_{2}$ nanotubes: an experimental study in the pig. J Biomed Mater Res B Appl Biomater. 2009;89(1):165-171.

45. Sreekantan S, Saharudin KA, Wei LC. Formation of $\mathrm{TiO}_{2}$ nanotubes via anodization and potential applications for photocatalysts, biomedical materials, and photoelectrochemical cell. IOP Conf Series Mater Sci Eng. 2011;21(1):012002.

46. Tsuchiya H, Macak JM, Taveira L, Ghicov A, Schmuki P. Hydroxyapatite growth on anodic $\mathrm{TiO}_{2}$ nanotubes. J Biomed Mater Res. 2006;77(3):534-541.

47. Yasuda K, Schmuki P. Formation of Self-Organized Zirconium Titanate Nanotube Layers by Alloy Anodization. Adv Mater. 2007;19(13):1757-1760.

48. Feng XJ, Macak JM, Albu SP, Schmuki P. Electrochemical formation of self-organized anodic nanotube coating on Ti-28Zr-8Nb biomedical alloy surface. Acta Biomater. 2008;4(2):318-323.

49. Yang $\mathrm{Y}$, Kim D, Yang M, Schmuki P. Vertically aligned mixed $\mathrm{V}_{2} \mathrm{O}_{5}$ $\mathrm{TiO}_{2}$ nanotube arrays for supercapacitor applications. Chem Commun. 2011;47:7746-7748.

50. Jha H, Hahn R, Schmuki P. Ultrafast oxide nanotube formation on TiNb, TiZr and TiTa alloys by rapid breakdown anodization. Electrochima Acta. 2010;55(28):8883-8887.

51. Tsuchiya $\mathrm{H}$, Schmuki P. Thick self-organized porous zirconium oxide formed in $\mathrm{H}_{2} \mathrm{SO}_{4} / \mathrm{NH}_{4} \mathrm{~F}$ electrolytes. Electrochem Commun. 2004;6(11):1131-1134.

52. Allam NK, Feng XJ, Grimes CA. Self-Assembled Fabrication of Vertically Oriented $\mathrm{Ta}_{2} \mathrm{O}_{5}$ Nanotube Arrays, and Membranes Thereof, by OneStep Tantalum Anodization. Chem Mater. 2008;20(20):6477-6481.

53. Tsuchiya $\mathrm{H}$, Schmuki P. Self-organized high aspect ratio porous hafnium oxide prepared by electrochemical anodization. Eletrochem Commun. 2005;7(1):49-52.

54. Sieber I, Hildebrand H, Friedrich A, Schmuki P. Formation of selforganized niobium porous oxide on niobium. Electrochem Commun. 2005;7(1):97-100.

55. Turhan MC, Lynch RP, Jha H, Schmuki P, Virtanen S. Anodic growth of self-ordered magnesium oxy-fluoride nanoporous/tubular layers on Mg alloy (WE43). Electrochem Commun. 2010;12(6):796-799.

56. Beranek R, Hildebrand H, Schmuki P. Self-organized porous titanium oxide prepared in $\mathrm{H}_{2} \mathrm{SO}_{4} / \mathrm{HF}$ electrolytes. Electrochem Solid-State Lett. 2003;6(3):B12-B14.

57. Masuda H, Fukuda K. Ordered metal nanohole arrays made by a twostep replication of honeycomb structures of anodic alumina. Science. 1995;268(5216):1466-1468.

58. Lee W, Ji R, Gösele U, Nielsch K. Fast fabrication of long-range ordered porous alumina membranes by hard anodization. Nat Mater. 2006;5: 741-747.

59. Lee W, Schwirn K, Steinhart M, Pippel E, Scholz R, Gösele U. Structural engineering of nanoporous anodic aluminium oxide by pulse anodization of aluminium. Nat Nanotechnol. 2008;3:234-239.

60. Hebert KR, Albu SP, Paramasivam I, Schmuki P. Morphological instability leading to formation of porous anodic oxide films. Nat Mater. 2012;11:162-166.

61. Masuda H, Ohya M, Asoh H, Nakao M, Nohtomi M, Tamamura T. Photonic Crystal Using Anodic Porous Alumina. Jpn J Appl Phys. 1998;38:L1403-L1405.

62. Takayama O, Cada M. Two-dimensional metallic-dielectric photonic crystals embedded in anodic porous alumina for optical wavelengths. Appl Phys Lett. 2004;85(8):1311-1313.

63. Houser JE, Hebert KR. The role of viscous flow of oxide in the growth of self-ordered porous anodic alumina films. Nat Mater. 2009;8:415-420. 
64. Yamaguchi A, Uejo F, Yoda T, et al. Self-assembly of a silicasurfactant nanocomposite in a porous alumina membrane. Nat Mater. 2004;3(5):337-341.

65. Steinhart M, Wendorff JH, Greiner A, et al. Polymer nanotubes by wetting of ordered porous templates. Science. 2002;296(5575):1997-1999.

66. Kelly JJ. The influence of fluoride ions on the passive dissolution of titanium. Electrochimica Acta. 1979;24(12):1273-1282.

67. Zwilling V, Aucouturier M, Darque-Ceretti E. Anodic oxidation of titanium and TA6V alloy in chromic media. An electrochemical approach. Electrochimica Acta. 1999;45(6):921-929.

68. Yasuda K, Macak JM, Berger S, Ghicov A, Schmuki P. Mechanistic aspects of the self-organization process for oxide nanotube formation on valve metals. J Electrochem Soc. 2007;154(9):C472-C478.

69. Macak JM, Tsuchiya H, Taveira L, Aldabergerova S, Schmuki P. Smooth anodic $\mathrm{TiO}_{2}$ nanotubes. Angew Chem Int Ed. 2005;44:7463-7465.

70. Macak JM, Hildebrand H, Marten-Jahns U, Schmuki P. Mechanistic aspects and growth of large diameter self-organized $\mathrm{TiO}_{2}$ nanotubes. J Electroanal Chem. 2008;621:254-266.

71. Albu SP, Ghicov A, Schmuki P. High aspect ratio, self-ordered iron oxide nanopores formed by anodization of $\mathrm{Fe}$ in ethylene glycol $/ \mathrm{NH}_{4} \mathrm{~F}$ electrolytes. Phys Status Solidi RRL. 2009;3:64-66.

72. Macak JM, Tsuchiya H, Taveira L, Ghicov A, Schmuki P. Selforganized nanotubular oxide layers on Ti-6Al-7Nb and Ti-6Al-4V formed by anodization in $\mathrm{NH}_{4} \mathrm{~F}$ solutions. $J$ Biomed Mater Res A. 2005;75(4):928-933.

73. Minagar S, Berndt CC, Wang J, Ivanova E, Wen C. A review of the application of anodization for the fabrication of nanotubes on metal implant surfaces. Acta Biomater. 2012;8(8):2875-2888.

74. Minagar S, Berndt CC, Gengenbach T, Wen C. Fabrication and characterization of $\mathrm{TiO}_{2}-\mathrm{ZrO}_{2}-\mathrm{ZrTiO}_{3}$ nanotubes on TiZr alloy manufactured via anodization. J Mater Chem B. 2014;2:71-83.

75. Lee WJ, Smyrl WH. Zirconium oxide nanotube synthesized via direct electrochemical anodization. Electrochem Solid-State Lett. 2005;8(3):B7-B9.

76. Berger S, Faltenbacher J, Bauer S, Schmuki P. Enhanced self-ordering of anodic $\mathrm{ZrO}_{2}$ nanotubes in inorganic and organic electrolytes using two-step anodization. Phys Status Solidi Rapid Res Lett. 2008;2(3): $102-104$.

77. Oh S, Finõnes RR, Daraio C, Chen L, Jin S. Growth of nano-scale hydroxyapatite using chemically treated titanium oxide nanotubes. Biomaterials. 2005;26(24):4938-4943.

78. Wang LN, Adams A, Luo JL. Enhancement of the capability of hydroxyapatite formation on $\mathrm{Zr}$ with anodic $\mathrm{ZrO}_{2}$ nanotubular arrays via an effective dipping pretreatment. J Biomed Mater Res B Appl Biomater. 2011;99(2):291-301.

79. Wang LN, Luo JL. Enhancing the bioactivity of zirconium with the coating of anodized $\mathrm{ZrO}_{2}$ nanotubular arrays prepared in phosphate containing electrolyte. Electrochem Commun. 2010;12(11):1559-1562.

80. Park J, Sebastian B, von der Mark K, Schmuki P. Nanosize and vitality: $\mathrm{TiO}_{2}$ nanotube diameter directs cell fate. Nano Lett. 2007;7(6): 1686-1691.

81. Bauer S, Park J, Faltenbacher J, Berger S, von der Mark K, Schmuki P. Size selective behavior of mesenchymal stem cells on $\mathrm{ZrO}_{2}$ and $\mathrm{TiO}_{2}$ nanotube arrays. Integr Biol (Camb). 2009;1(8-9):525-532.

82. Oh S, Brammer KS, Li YS, et al. Stem cell fate dictated solely by altered nanotube dimension. Proc Natl Acad Sci U S A. 2009;106(7): 2130-2135.

International Journal of Nanomedicine

\section{Publish your work in this journal}

The International Journal of Nanomedicine is an international, peerreviewed journal focusing on the application of nanotechnology in diagnostics, therapeutics, and drug delivery systems throughout the biomedical field. This journal is indexed on PubMed Central, MedLine, CAS, SciSearch $\AA$, Current Contents ${ }^{\circledR} /$ Clinical Medicine,
83. Brammer KS, Frandsen $\mathrm{CJ}$, Jin $\mathrm{S}$. $\mathrm{TiO}_{2}$ nanotubes for bone regeneration. Trends Biotechnol. 2012;30(6):315-322.

84. Lai M, Cai K, Zhao L, Chen X, Hou Y, Yang Z. Surface functionalization of $\mathrm{TiO}_{2}$ nanotubes with bone morphogenetic protein 2 and its synergistic effect on the differentiation of mesenchymal stem cells. Biomacromlolecules. 2011;12(4):1097-1105.

85. Bauer S, Park J, Mark K, Schmuki P. Improved attachment of mesenchymal stem cells on super-hydrophobic $\mathrm{TiO}_{2}$ nanotubes. Acta Biomater. 2008;4(5):1576-1582

86. Bauer S, Park J, Pittrof A, Song Y, von der Mark K, Schmuki P. Covalent functionalization of $\mathrm{TiO}_{2}$ nanotube arrays with EGF and BMP-2 for modified behavior towards mesenchymal stem cells. Integr Biol (Camb). 2011;3(9):927-936.

87. Brammer KS, Choi C, Frandsen CJ, Oh S, Johnston G, Jin S. Comparative cell behavior on carbon-coated $\mathrm{TiO}_{2}$ nanotube surfaces for osetoblasts vs osteo-progenitor cells. Acta Biomater. 2011;7(6):2697-2703.

88. Yao C, Storey D, Webster TJ. Nanostructured metal coatings on polymers increase osteoblast attachment. Int $J$ Nanomedicine. 2007;2(3):487-492.

89. Wang N, Li H, Wang J, Chen S, Ma Y, Zhang Z. Study on the anticorrosion, biocompatibility, and osteoinductivity of tantalum decorated with tantalum oxide nanotube array films. ACS Appl Mater Interfaces. 2012;4(9):4516-4523.

90. Song YY, Schmidt-Stein F, Bauer S, Schmuki P. Amphiphilic $\mathrm{TiO}_{2}$ nanotube arrays: an actively controllable drug delivery system. J Am Chem Soc. 2009;131(12):4230-4232.

91. Peng L, Mendelsohn AD, LaTempa TJ, et al. Long-term small molecule and protein elution from $\mathrm{TiO}_{2}$ nanotubes. Nano Lett. 2009;9(5): 1932-1936.

92. Popat KC, Eltgroth M, LaTempa TJ, Grimes CA, Desai TA. Titania nanotubes: a novel platform for drug eluting coatings for medical implants? Small. 2007;3(11):1878-1881.

93. Popat KC, Eltgroth M, LaTempa TJ, Grimes CA, Desai TA. Decreased Staphylococcus epidermis adhesion and increased osteoblast functionality on antibiotic-loaded titania nanotubes. Biomaterials. 2007;28(32):4880-4888.

94. Yao C, Webster TJ. Prolonged antibiotic delivery from anodized nanotubular titanium using a co-precipitation drug loading method. J Biomed Mater Res B Appl Biomater. 2009;91(2):587-595.

95. $\mathrm{Hu} \mathrm{Y}$, Cai $\mathrm{K}$, Luo Z, et al. $\mathrm{TiO}_{2}$ nanotubes as drug nanoreservoirs for the regulation of mobility and differentiation of mesenchymal stem cells. Acta Biomater. 2012;8(1):439-448.

96. Shrestha NK, Macak JM, Schmidt-Stein F, et al. Magnetically guided titania nanotubes for site-selective photocatalysis and drug release. Angew Chem Int Ed Engl. 2009;48(5):969-972.

97. Bjursten LM, Rasmusson L, Oh S, Smith GC, Brammer KS, Jin S. Titanium dioxide nanotubes enhance bone bonding in vivo. J Biomed Mater Res. 2010;92(3):1218-1224.

98. Soumetz FC, Pastorino L, Ruggiero C. Human osteoblast-like cells response to nanofunctionalized surfaces for tissue engineering. J Biomed Mater Res B Appl Biomater. 2008;84(1):249-255.

99. Sundelacruz S, Kaplan DL. Stem cell- and scaffold-based tissue engineering approaches to osteochondral regenerative medicine. Semin Cell Dev Biol. 2009;20(6):646-655.

Journal Citation Reports/Science Edition, EMBase, Scopus and the Elsevier Bibliographic databases. The manuscript management system is completely online and includes a very quick and fair peer-review system, which is all easy to use. Visit http://www.dovepress.com/ testimonials.php to read real quotes from published authors. 